OPEN ACCESS

Edited by: Steven O'Reilly,

STipe Therapeutics, Denmark

Reviewed by: Dhiraj Kumar Singh, Southwest National Primate Research Center (SNPRC), United States

Stamatis-Nick C. Liossis, General University Hospital of Patras, Greece Kavitha Mukund University of California, San Diego, United States

*Correspondence:

Athanasios G. Tzioufas agtzi@med.uoa.gr

${ }^{t}$ These authors share senior authorship

Specialty section: This article was submitted to Autoimmune and Autoinflammatory Disorders, a section of the journal

Frontiers in Immunology

Received: 01 June 2021 Accepted: 09 August 2021 Published: 26 August 2021

Citation:

Kaklamanos A, Belogiannis $K$, Skendros $P$, Gorgoulis VG, Vlachoyiannopoulos $P G$ and Tzioufas AG (2021) COVID-19

Immunobiology: Lessons Learned, New Questions Arise.

Front. Immunol. 12:719023 doi: 10.3389/fimmu.2021.719023

\section{COVID-19 Immunobiology: Lessons Learned, New Questions Arise}

\author{
Aimilios Kaklamanos ${ }^{1,2}$, Konstantinos Belogiannis ${ }^{3}$, Panagiotis Skendros ${ }^{4}$, \\ Vassilis G. Gorgoulis ${ }^{3,5,6,7 t}$, Panayiotis G. Vlachoyiannopoulos ${ }^{1,2 \dagger}$ \\ and Athanasios G. Tzioufas ${ }^{1,2 * t}$
}

\begin{abstract}
${ }^{1}$ Department of Pathophysiology, School of Medicine, National and Kapodistrian University of Athens, Athens, Greece, 2 Institute for Autoimmune Systemic and Neurological Diseases, Athens, Greece, ${ }^{3}$ Molecular Carcinogenesis Group, Department of Histology and Embryology, School of Medicine, National and Kapodistrian University of Athens, Athens, Greece, ${ }^{4}$ First Department of Internal Medicine and Laboratory of Molecular Hematology, University Hospital of Alexandroupolis, Democritus University of Thrace, Alexandroupolis, Greece, ${ }^{5}$ Faculty Institute for Cancer Sciences, Manchester Academic Health Sciences Centre, University of Manchester, Manchester, United Kingdom, ${ }^{6}$ Basic Research Center, Biomedical Research Foundation of the Academy of Athens (BRFAA), Athens, Greece, ${ }^{7}$ Center for New Biotechnologies and Precision Medicine, School of Medicine, National and Kapodistrian University of Athens, Athens, Greece
\end{abstract}

There is strong evidence that COVID-19 pathophysiology is mainly driven by a spatiotemporal immune deregulation. Both its phenotypic heterogeneity, spanning from asymptomatic to severe disease/death, and its associated mortality, are dictated by and linked to maladaptive innate and adaptive immune responses against SARS-CoV-2, the etiologic factor of the disease. Deregulated interferon and cytokine responses, with the contribution of immune and cellular stress-response mediators (like cellular senescence or uncontrolled inflammatory cell death), result in innate and adaptive immune system malfunction, endothelial activation and inflammation (endothelitis), as well as immunothrombosis (with enhanced platelet activation, NET production/release and complement hyper-activation). All these factors play key roles in the development of severe COVID-19. Interestingly, another consequence of this immune deregulation, is the production of autoantibodies and the subsequent development of autoimmune phenomena observed in some COVID-19 patients with severe disease. These new aspects of the disease that are now emerging (like autoimmunity and cellular senescence), could offer us new opportunities in the field of disease prevention and treatment. Simultaneously, lessons already learned from the immunobiology of COVID-19 could offer new insights, not only for this disease, but also for a variety of chronic inflammatory responses observed in autoimmune and (auto)inflammatory diseases.

Keywords: SARS-CoV-2, COVID-19, immune deregulation, immunothrombosis, senescence, endothelitis, autoimmunity

\section{INTRODUCTION}

Coronavirus Disease-2019 (COVID-19) has costed millions of lives worldwide. Since the beginning of the pandemic, the scientific community has joined forces to understand the pathophysiology of the disease, aiming to develop effective preventive and therapeutic measures. The development of many vaccines complementing social and personal protective measures (distancing, masks, hand 
washing etc.) coupled with pharmacologic treatments (heparin, dexamethasone, remdesivir and others), constitute our current armamentarium against Severe Acute Respiratory Syndrome Coronavirus-2 (SARS-CoV-2). Despite such a collective effort, we are still far from altering the disease's clinical course, particularly the devastating course of many cases. In this review, we will summarise, in a step-by-step approach, the existing evidence regarding the key pathophysiological processes that take place from viral inhalation to disease establishment in all its forms, with emphasis on the immunopathology of the disease and the differences among the diverse clinical courses. Lessons learned from the immunopathology of COVID-19 hitherto, including the interplay between innate and adaptive immune responses, the immunemediated thrombosis, panoptosis, autoimmunity and cellular senescence, could offer new insights, not only for the disease per se, but also for a variety of chronic inflammatory responses observed in autoimmune and (auto)inflammatory diseases.

\section{SARS-COV-2: FROM INHALATION TO COVID-19}

\section{Viral Effects on the Respiratory System}

SARS-CoV-2 is responsible for the so-called COVID-19, an airborne disease affecting initially the respiratory tract and eventually leading to a systemic disorder (1) (Table 1) (2-12). Through inhalation of air droplets and/or direct virus inoculation on mucosal surfaces, this novel viral strain can infect specific cells, of both the upper and lower respiratory tract, particularly those expressing high numbers of the Angiotensin Converting Enzyme2 (ACE-2) receptor (Figure 1) (14-18). The ciliated epithelial cells appear particularly sensitive to this virus. Moving along the airways towards the lower parts of the respiratory tract, ACE-2 expression levels drop steadily, resulting in lower infection rates of type II pneumocytes (19). Ciliated epithelial cells and type II pneumocytes along with the resident lung macrophages -both alveolar and interstitial types- and vascular endothelial cells, are the main cellular targets for SARS-CoV-2 in the respiratory system $(20,21)$. Beyond the respiratory system, ACE2 has a ubiquitous expression in other human tissues and organs including the heart, kidney, intestine, vessels, liver, central nervous system, eyes etc. (22), and therefore, SARS-CoV-2 can potentially invade many different cells/tissues. Following the endocytosis of SARS-CoV-2 coupled with its receptor ACE2, the number of available molecules of ACE2 on cell membrane is reduced (20). As a result, the circulating angiotensin II is not degraded to angiotensin $\sin _{1-7}$ and the consequences of this phenomenon are depicted in Figure 2 (20, 23-25, 27-30).

In parallel, viral infection of host cells activates both the innate and adaptive arms of the immune system, mounting an immune response against SARS-CoV-2. Robust aberrant cellular alterations, including cellular senescence (31), apoptosis, with emphasis in the inflammatory subtypes thereof [pyroptosis (32), necroptosis (33), PANoptosis (34)] and NETosis are implicated in the disease course and severity.

\section{Innate Immune Response Against SARS-CoV-2}

Innate Immunity, which is the first line of defence in response to infection, is initiated by Pattern Recognition Receptors (PRRs)mediated identification of Damage-Associated Molecular Patterns (DAMPs) and Pathogen-Associated Molecular Patterns (PAMPs). The former are released by the infected cell and the latter are virus-associated molecules, such as ssRNA, acting as danger signals, which eventually activate the immune system. More specifically, as depicted in Figure 3 (35, 36), Tolllike receptors (TLRs) bind their ligands, and subsequently activate cytosolic RLRs and NLRs (37-39), leading to the production of interferons, cytokines and chemokines.

The earliest innate antiviral events, occurring within hours post infection, are Type I and Type III Interferon (IFN)responses, that act as barriers to viral replication and

TABLE 1 | COVID-19 is a systemic disease affecting many different organs/systems.

\begin{tabular}{|c|c|}
\hline Systemic symptoms (2) & $\begin{array}{l}\text { Mild: fever, malaise, fatigue, cough, dyspnea, chest pain, nasal congestion, and sore throat } \\
\text { Severe: pneumonia, pulmonary edema, acute respiratory failure, ARDS, sepsis, multiorgan failure, shock, and death }\end{array}$ \\
\hline cardiovascular system (3-5) & $\begin{array}{l}\text { myocardial injury, myocarditis, acute coronary syndrome, heart failure, arrhythmia, sudden cardiac death, or thrombosis with } \\
\text { subsequent thromboembolic events like ischemia, deep venous thrombosis and pulmonary embolism }\end{array}$ \\
\hline gastrointestinal system $(6,7)$ & $\begin{array}{l}\text { loss of appetite, diarrhea, nausea, vomiting and abdominal pain, elevated liver enzymes (bilirubin, AST, ALT), while the virus can be } \\
\text { found in stool samples }\end{array}$ \\
\hline kidneys (8) & acute kidney injury \\
\hline nervous system (9) & $\begin{array}{l}\text { headache, dizziness, anosmia, ageusia, encephalopathy, encephalitis, ischemic stroke, neuroinflammation or rarely immune-mediated } \\
\text { complications such as ADEM, acute necrotizing hemorrhagic encephalopathy or Guillain-Barre syndrome }\end{array}$ \\
\hline skin (10) & $\begin{array}{l}\text { maculopapular, morbilliform, urticarial, vesicular, chilblain-like, petechiae/purpura and livedoid, or maculo-papular, or erythema } \\
\text { multiforme-like, or diffuse erythroderma rash associated with a hyperinflammatory Kawasaki-like syndrome in children }\end{array}$ \\
\hline muscular system (11) & myopathy \\
\hline hematologic parameters (12) & elevated CRP - LDH - ferritin - CK levels, decreased albumin and elevated levels of various inflammatory cytokines like TNF $\alpha$ and IL-6 \\
\hline
\end{tabular}




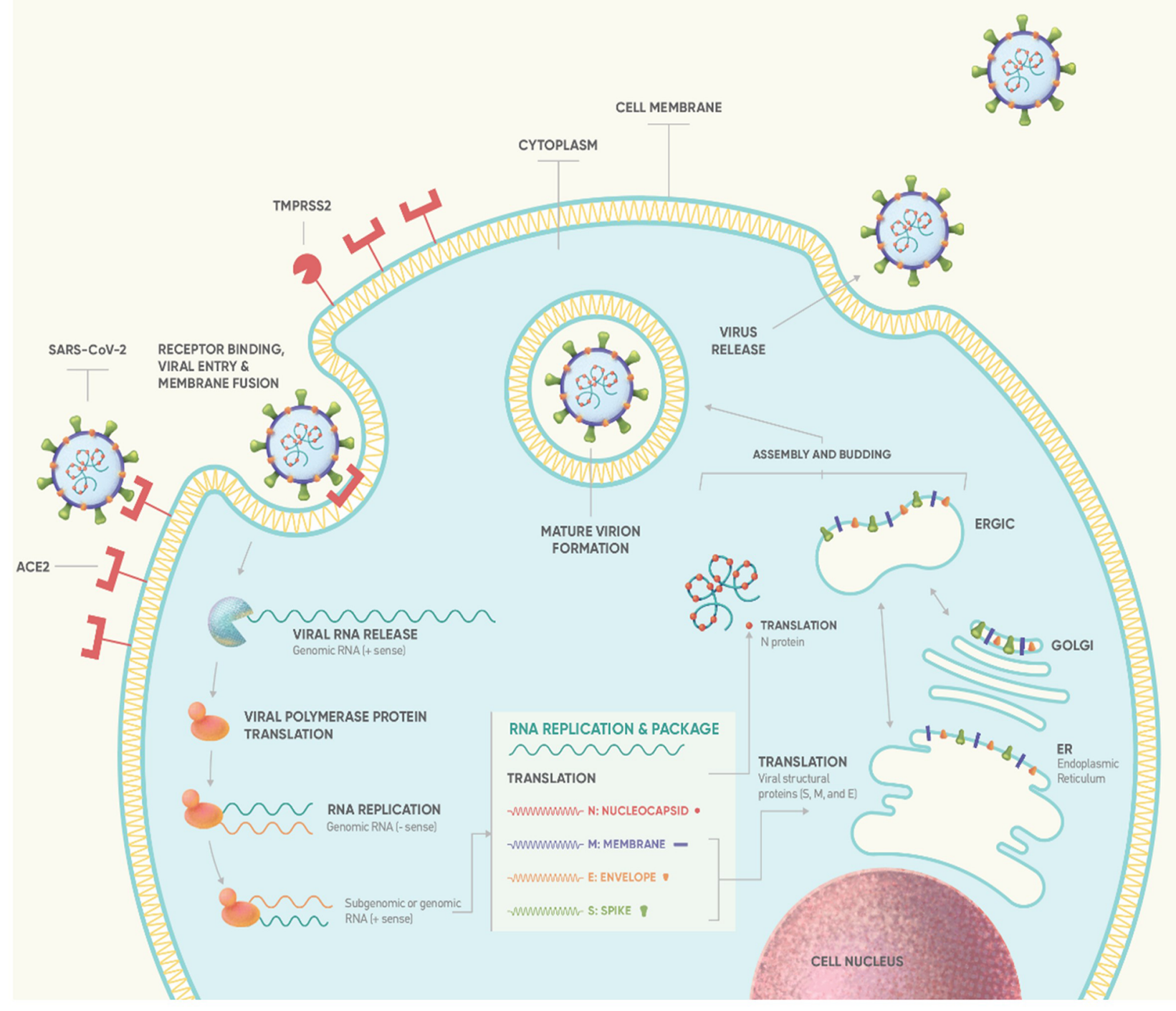

FIGURE 1 | Life cycle of SARS-CoV-2 (13). Binding of S protein to ACE2 receptor induces the proteolytic cleavage of S protein by cell surface-associated transmembrane protease serine 2 (TMPRSS2) and cathepsin. S1-RBD is recognized by ACE2 (14), mediating virus fusion and entry into the target cell via endocytosis $(13,15)$. Subsequently, the virus releases its positive-sense RNA-strand into the cytoplasm which serves as template to produce full length negativesense RNAs by a reaction catalyzed by RTC. Using ribosomes of infected cell, virus ORF1a and ORF1ab are translated producing the pp1a and pp1ab polyproteins. Replication of viral RNA and N protein is then followed, mediating the packaging of viral RNA. Simultaneously, genes encoding S, M and E protein are transcribed and translated in the ER and transported to Golgi complex to form ER-Golgi intermediate compartment (ERGIC). Virus assembly and budding is mediated through the interaction between the RNA-N complex and the ERGIC creating a mature virion. Finally, the newly formed virion is released from host cell via exocytosis (13, 15, 16). According to estimated data of viral dynamics during in vitro experiments, SARS-CoV-2 requires approximately 10 min to enter susceptible cell lines and about 10hrs to replicate intracellularly (the so-called eclipse period) such that $10^{3}$ progeny virions are released from a single cell ('burst' size: $\sim 10^{3}$ ) through continuous budding (17). ACE2, angiotensin-converting enzyme 2; ER, endoplasmic reticulum; RBD, receptor-binding domain; RTC, replicase-transcriptase complex.

dissemination. Type I interferons can directly inhibit the viral replication and enhance both innate and adaptive immunity, via various mechanisms, including: 1) MX1-GTPase polymerization, 2) IFN-inducible dsRNA-dependent protein kinase R (PKR), 3) 2'-5'- oligoadenylatesynthetase (OAS), 4) IFN-induced transmembrane protein (IFITMs), 5) APOBEC1 and the TRIM family of molecules (40). The main cellular source of type I IFNs in response to SARS-CoV-2, appears to be the plasmacytoid Dentritic Cells (pDCs), activated via the TLR7, as is the case for other coronaviruses (41).

These pathways have attracted the attention of current research since coronaviruses $(\mathrm{CoVs})$ possess an intrinsic capacity to interfere with various IFN pathway-related molecules. Indeed, the implementation of specific structural and non-structural proteins has revealed that SARS-CoV-2 induces diminished or delayed Type I Interferon responses (42-44), 


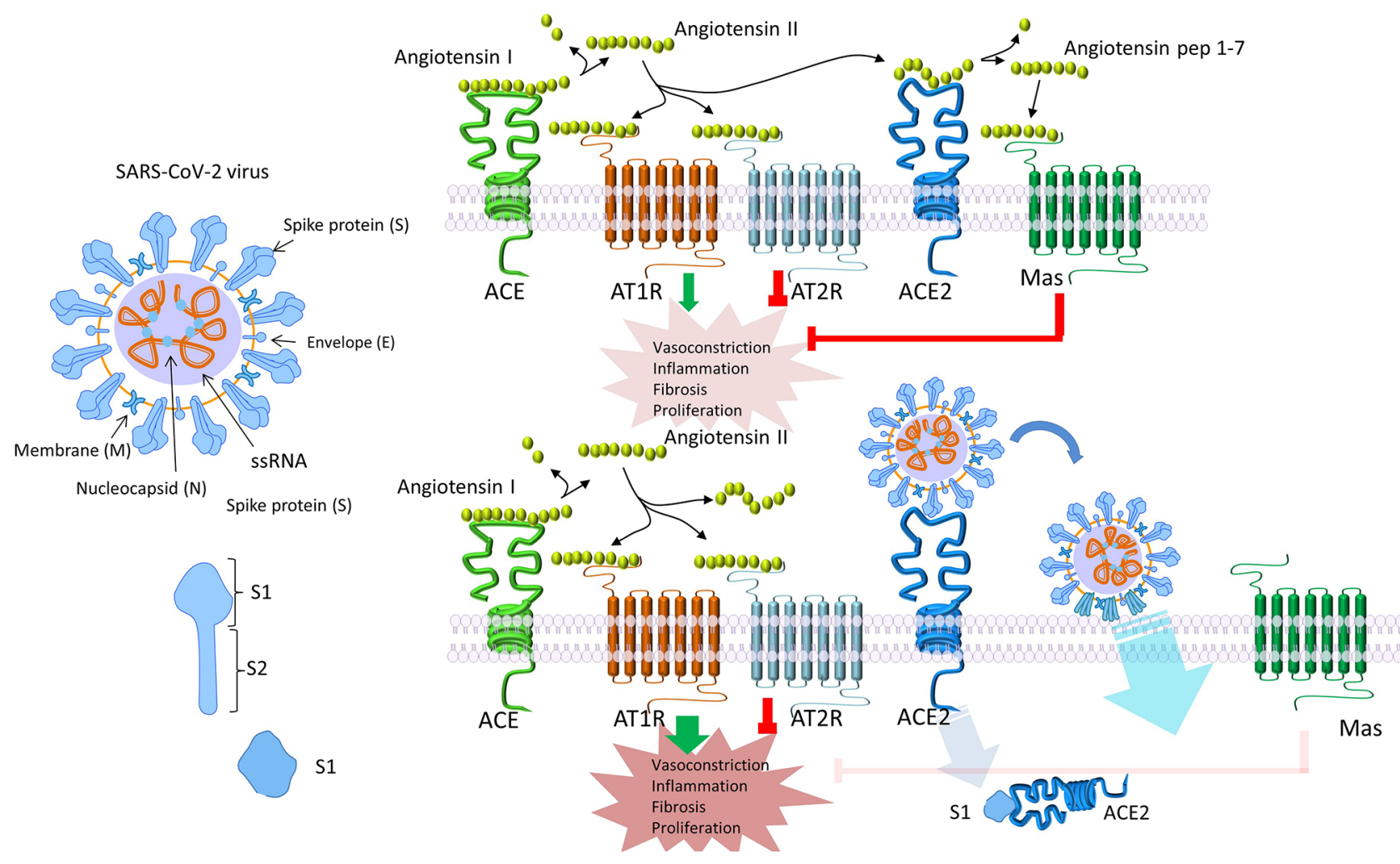

FIGURE 2 | SARS-CoV-2 endocytosis alters angiotensin II signaling. Following endocytosis of SARS-CoV-2 together with its receptor ACE2, the number of available ACE2 molecules on the cell membrane is decreased (20). As a result, circulating angiotensin II is not degraded to angiotensin ${ }_{1-7}$. Angiotensin II signals mainly through AT1, while angiotensin ${ }_{1-7}$ through AT2 and Mas receptors. Signaling through AT1, increases vasoconstriction and interstitial fibrosis, enhances inflammation by macrophage activation and, eventually, the production of inflammatory cytokines, induces endothelial dysfunction, and increases pulmonary permeability leading to pulmonary edema and ARDS (23). Reduced expression of ACE2 can indirectly activate the kinin-kallikrein system, leading to increased vascular permeability (24). Simultaneously, downregulation of ACE2 has been connected to myocardial hypertrophy and dysfunction, obesity-associated hypertension and increased oxidative stress $(20,25,26)$. Interestingly, in many conditions which serve as high risk factors for COVID-19, like increased age, male gender, obesity, diabetes mellitus, arterial hypertension, and heart insufficiency, ACE2 is downregulated or deficient (20, 27-29). The subsequent, already increased AT1 signaling, could, at least partially, explain the increased risk and the worse clinical progression of COVID-19 in these patients (20). To the contrary, signaling through AT2 or Mas receptors, has the opposite effects and therefore seems to confer a protection against angiotensin II-AT1 signaling (20, 30). ACE2, angiotensin-converting enzyme 2; AT, angiotensin II receptor.

thus generating, early in the disease course, a replication permissive microenvironment. This phenomenon probably explains the high viral loads upon the onset of disease symptoms seen in COVID-19 patients (41), the unusually long viral incubation time and the high rates of asymptomatic or pauci-symptomatic patients (44). The mechanisms utilized by the coronaviruses to evade the initial immune recognition and response via IFNs can be divided into three categories: (1) avoidance of the recognition by the PRRs, (2) suppression of the transcription of interferons, and (3) the suppression of IFN signaling by the viral proteins through inhibition of IFNAR signaling or autoantibodies against IFN pathway elements that neutralize IFN actions. The precise mechanisms used by SARSCoV-2 are yet unknown, but their majority is expected to share the same basis among different coronaviruses (45) as shown in Figure $4(35,41,46)$. In addition to these mechanisms, SARSCoV-2 uses its own capping machinery (nsp10, nsp13, nsp16), to generate 2-o-methyltransferase caps. These RNA caps are indistinguishable from cellular mRNA caps, therefore, the RNA detection and degradation by the type I IFN-inducible proteins, MDA-5 and IFIT, are circumvented. Furthermore, SARS-CoV-2 uses replicase-transcriptase complexes that protect the virus during the maturation process. Moreover, corona viruses use glycans and/or other post-translational modifications to mask the immunogenic viral protein epitopes (35). SARS-CoV-2 can also infect antigen-presenting cells (APCs), inducing epigenetic changes that cause an HLA-II downregulation, as described in both monocytes/macrophages, and B cells (47), probably via an IL-6-dependent pathway (48). Furthermore, the blockade of interferon signaling limits the Interferon-Stimulated Genes (ISGs) expression in APCs, including the cytokine-induced MHC-II expression. Moreover, SARS-CoV-2 protein Nsp5 interacts with the epigenetic regulator Histone Deacetylase 2 (HDAC2), which controls the MHC-II expression and cytokine production $(49,50)$. Finally, ORF8 of SARS-CoV-2 can directly bind to MHC-I molecules in the ER, redirecting 

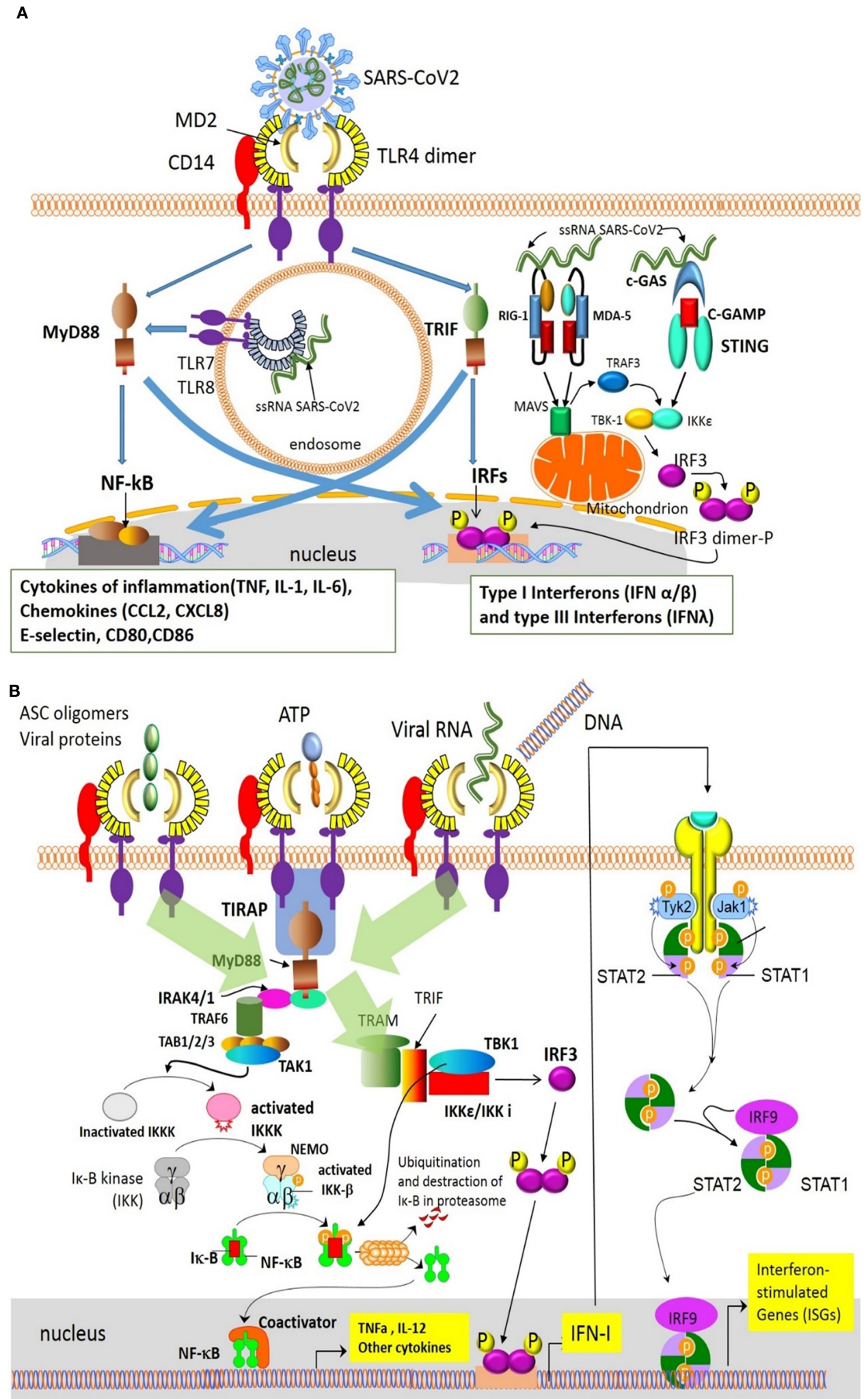

FIGURE 3 | Continued 
FIGURE 3 | Innate immune detection of SARS-CoV-2 results in the production of interferons, cytokines and chemokines (35). Innate immune cells detect SARS-CoV-2 via different mechanisms/pathways. (A) Viral RNA activates the MyD88-NF-kB and IRF pathways inducing production of inflammatory cytokines and type I interferons. Additionally, the cGAS-STING and the MDA-5/RIG-I pathways, also sense the cytoplasmic viral RNA or viral replicative intermediates, and lead to the production of type and III interferons (IFNa/ $\beta$ and IFN $\lambda$ ). In turn, these interferons, acting in an autocrine/paracrine way via the IFNAR1/2 or IFNAR2/IL10R pathways, induce the expression of ISGs. (B) PRRs like TLR4 also recognize PAMPs-DAMPs released by damaged cells and induce the production of inflammatory cytokines through the NF-kB pathway (36). ASC, apoptosis-associated speck-like protein containing a CARD; cGAMP, cyclic GMP-AMP; cGAS, cyclic GMP-AMP Synthase; DAMPs, damage-associated molecular patterns; IFN, interferon; IFNAR, interferon receptor; IKK, inhibitor of NFkB; IRAK, IL-1R associated kinase; IL10R,interleukin-10 receptor; IRF, interferon regulatory factor; ISGs, interferon-stimulated genes; Jak, Janus kinase; MAVS, mitochondrial antiviral-signaling protein; MD2, myeloid differentiation factor 2; MDA-5, melanoma differentiation-associated gene 5; MyD88, Myeloid differentiation primary response 88; NEMO, NFkB essential modulator; NF-kB, nuclear factor kappa B; PAMPs, pathogen-associated molecular patterns; PRRs, Pattern Recognition Receptors; RIG-I, retinoid inducible gene I; STAT, Signal transducer and activator of transcription; STING, Stimulator of Interferon Genes; TAB, Mitogen-activated protein kinase kinase binding protein; TAK1, TGF $\beta$-activated kinase 1; TBK-1, TANK-binding kinase 1; TIRAP, Toll-interleukin 1 receptor (TIR) domain containing adaptor protein; TLR4, Toll-like receptor 4; TRAM, Translocating chain-associated membrane protein; TRAF, TNF receptor-associated factor; TRIF, TIR-domain-containing adapter-inducing interferon- $\beta$; Tyk, Tyrosine kinase.

them to autolysosomes for degradation and resulting in the inefficient elimination of the virus by Cytotoxic Lymphocytes (CTLs) (46).

Normally, Type I and III IFN responses activate and augment the function of immune system tissue resident cells including dendritic cells, alveolar and interstitial tissue resident macrophages and Natural Killer cells (NK-cells). For example, monocytes/macrophages phagocytose the infected cells and induce type I IFN responses and pro-inflammatory molecules. NK cells recognize peptides expressed on the surface of infected cells and destroy them via direct cytotoxicity, through perforins and granzyme B. All immune cells release cytokines and chemokines, such as among others, TNF-a, IL1 $\beta$, IL6 and IL8, that amplify and propagate the immune response by recruiting more cells in the following time order: Neutrophils are recruited first (within 12-24 hours post-infection, usually peaking at day 2-3), followed by pDCs (41). Monocytes, T- and B-cells appear later, from day 4-5 onwards, thus switching the immune response to its adaptive arm.

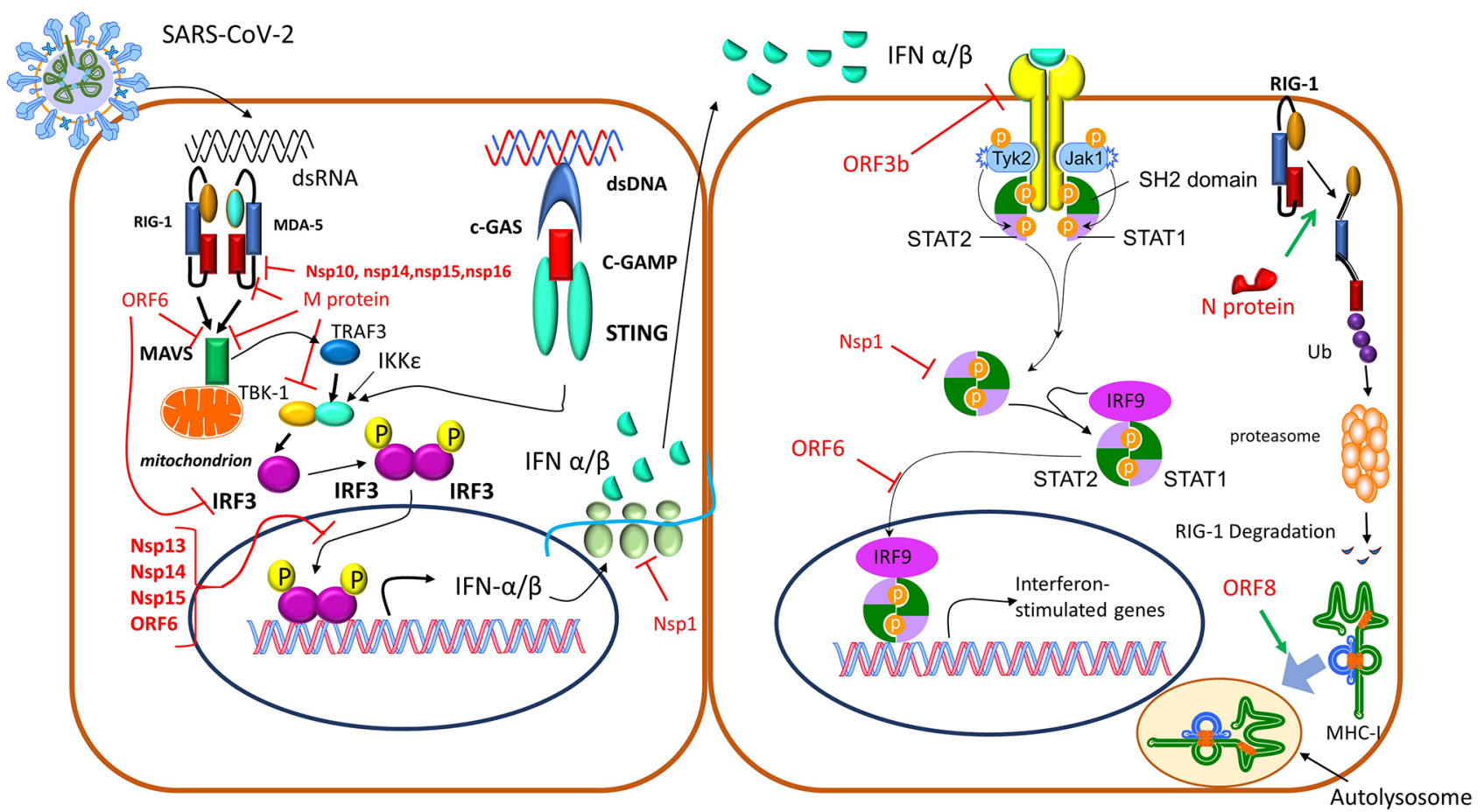

FIGURE 4 | Corona viruses exploit different mechanisms to avoid immune detection $(35,41,46)$. 1) The N protein-targeted ubiquitination drives RIG-I for proteasomal degradation, depleting the cell of a critical PRR. 2) Furthermore, the IFN pathway is inhibited by SARS-CoV-2' proteins through various mechanisms: a) ORF3b, highly expressed in the acute stage of the infection, downregulates the expression of IFNAR, and eventually IFN I responses. b) Nsp13, Nsp14, Nsp15, and ORF6 suppress IRF3 nuclear translocation, c) Nsp1, blocks mRNA translation and also decreases STAT phosphorylation, d) M protein as well as nsp10, nsp13, nsp14, nsp15, can inhibit the production of type I and III IFNs through interaction with the RIG-I/MDA-5-MAVS signaling pathway, e) ORF8 can directly bind to MHC I molecules at the endoplasmic reticulum and redirect them to autolysosomes for degradation, which results in its inefficient elimination by cytotoxic lymphocytes. IFN, interferon; IFNAR, interferon a receptor; IRF3, interferon regulatory factor 3; MAVS, mitochondrial antiviral-signaling protein; MDA-5, melanoma differentiationassociated gene 5; MHC, major histocompatibility complex; PRR, Pattern Recognition Receptor; RIG-I, retinoid inducible gene I; STAT, Signal transducer and activator of transcription. 
Adequate adaptive responses require approximately 6-10 days of priming, reflecting the physiological lag period (post innate pathogen sensing) that is needed for the generation of pathogenspecific T- and B- cell clonal selection (51).

In parallel, glycans attached on viral proteins that are expressed on the infected cell surface can activate the lectin complement pathway after binding on the Mannose-Binding Protein (MBP). Complement activation leads to further inflammatory cell activation and the generation of Membrane Attack Complex (C5b-C9) on the surface of alveolar and epithelial cells, resulting in their destruction (52).

\section{Adaptive Immune Response Against SARS-CoV-2}

A week after the onset of COVID-19 symptoms, if the above described mechanisms operate uninterrupted, adaptive immunity, - mediated by CD $4^{+} \mathrm{T}$-cells, $\mathrm{CD}^{+}$cytotoxic T-cells and antibodies -, is activated (53). Glycans expressed on SARSCoV-2 are recognized by DC-SIGN and other lectins, facilitating the viral uptake by DCs and pDCs, which in turn present viral antigens to $\mathrm{CD} 4^{+} \mathrm{T}$-helper cells. This results in a Th1 response with enhanced IFN- $\gamma$, IL- 2 and TNF $\alpha$ production/secretion (53, 54). $\mathrm{CD}^{+} \mathrm{T}$-cell responses specific to SARS-CoV-2 also produce IFN- $\gamma$, IL-2 and TNF $\alpha$, resulting in direct cytotoxicity against infected cells (55). Notably, memory T-cells have also been detected in individuals that do not produce antibodies against SARS-CoV-2, which suggests that cellular immunity operates together and/or independently of humoral immunity (55). Lymphocytes, and in particular $\mathrm{CD}^{+} \mathrm{T}$-cells, are the main regulators of the adaptive immune response against the invader, and their chemotaxis to the lungs might be partly responsible for the lymphopenia observed in the peripheral blood of many COVID-19 patients, a hallmark of COVID-19 $(56,57)$.

Follicular T-helper cells, through the formation of germinal centers and the provision of B-cells with all the necessary costimulatory molecules (such as CD40L and cytokines like IL-21), drive the humoral immunity towards SARS-CoV-2 surface glycoproteins, mainly glycoprotein $S$ and nucleocapsid protein $(58,59)$. Antibodies against the spike glycoprotein and especially its Receptor Binding Domain possess a neutralizing effect against SARS-CoV-2, preventing the binding of the virus to ACE2 (60). Usually the first antibodies produced are of the IgA class, during the first week of infection, followed by IgM (in 10-12 days) and after the first 3 weeks by IgG (61). Interestingly, approximately $10 \%$ of infected COVID-19 patients have no detectable antibodies even after the $4^{\text {th }}$ week post symptom onset, leading to the hypothesis that antibody production is not required for SARS-CoV-2 resolution in these so-called "non-responder" patients. This paradox is apparently not the case, and a possible mechanistic explanation in a subset of these patients could be the masking of antibodies due to prolonged antigenemia/viremia (62), or some - until now not described in COVID-19 - antiidiotypic response. Although the clinical significance of the initial titers of the produced antibodies and the duration of humoral immune response are still under investigation $(63,64)$, it is widely accepted that irrespective of disease severity, both $\mathrm{T}$ - and $\mathrm{B}$-cell function are critical for disease termination $(51,65)$.

\section{COVID-19 IMMUNOBIOLOGY}

\section{From Normal to Aberrant Host Immune Response}

In physiology, the immune response is well orchestrated in time and space (spatiotemporally), in a way that its ultimate actions resolution of damage, repair, and healing - are accomplished. Prerequisite for the latter is the counterbalance of proinflammatory actions with equal and opposite antiinflammatory actions. For reasons still under investigation, this is not the case for a significant number of COVID-19 patients who experience the severe or critical form of the disease. According to latest research findings, however, spatiotemporally dys-synchronised and deregulated immune responses -starting early at the level of Type I and III IFN responses- appear to support the immunopathogenesis of COVID-19, tipping the balance towards an excessive, uncontrolled viral replication and the subsequent robust release of cytokines with detrimental effects on the human tissues. A good example are patients with either inborn errors in type I interferon signaling, in the genes coding for TLR3, UNC93B1, TICAM1, TBK1, IRF3, IRF7, IFNAR1, IFNAR2 (66) or preexisting neutralizing autoantibodies against type I IFNs (67), who are at higher risk for life-threatening COVID-19 infection. Genetic predisposition is also regarded as a crucial element to explain the transition from normal to aberrant host immune responses in different COVID-19 patients. Numerous studies have identified such genetic susceptibility loci, like apolipoprotein $\mathrm{E}$ and the $\mathrm{ABO}$ blood group genes, but the importance of these findings has not been understood to its entirety hitherto (68).

Comparative studies between mild and severe disease are a prerequisite for understanding essential differences governing the phenotypic switch between different COVID-19 disease states and for deciphering its pathophysiology. Recent reports have shown, that the transition from mild to moderate and ultimately to severe disease phenotype is coupled with metabolic, as well as innate and adaptive immune alterations. Multiomic analysis of mild, moderate, and severe cases has revealed a pivotal change occurring between mild and moderate disease states, rendering the therapeutic interventions very critical at the moderate stage. This change is characterised by the emergence of unusual cell types, including preferentially exhausted CD $4^{+}$ T-cells, cytotoxic $\mathrm{CD}^{+}{ }^{-} \mathrm{T}$-cells, proliferative exhausted $\mathrm{CD} 8^{+}$ T-cells (loss of $\mathrm{CD}^{+}$T-cell poly-functionality), $\mathrm{S} 100^{\mathrm{High}} / \mathrm{HLA}$ $\mathrm{DR}^{\text {low }}$ monocytes and depletion of non-classical monocytes. This disturbance of cell populations is accompanied by metabolic depletion in lipids, amino acids and xenobiotics (69). Similarly, marked deregulation in lipid transport has also been shown by RNA-seq and high-resolution mass spectrometry, associated with abnormal complement activation, and neutrophil degranulation in severe cases (70). In line with that, two large 
multi-omic studies have demonstrated that in such critical cases, an abnormal myeloid cell compartment -associated with features of acute myelopoiesis with immature, dysfunctional neutrophils and monocytes- was observed $(71,72)$. Interestingly, both cell populations were reprogrammed to an anti-inflammatory or suppressive phenotype (71), which could reflect either a counter-regulatory attempt of the body to terminate the excessive inflammation or a futile attempt to eliminate the offending stimulus that persists. To this end, information around the timing of monocyte trafficking has also been studied with surge of $\mathrm{CD} 169^{+}$and re-appearance of $\mathrm{CD}^{+} 6^{+}$ monocytic cells to be linked with elevated CCL2 and CCL3 levels seen in severe rather than mild disease (73). In support to the aforementioned, a recent transcriptomic analysis in the lungs of COVID-19 cases has revealed relative absence of cytotoxic cell signatures, thus creating a permissive setting for enhanced myeloid-lineage cell involvement in the destructive sequelae accompanying the disease process (74). As opposed to mild cases, $\mathrm{CD}^{+}$cytotoxic T-cells displayed impaired exhaustion features with enhanced cytotoxicity and inflammation and a robust $\mathrm{CD}^{+} \mathrm{T}$ cell memory with unclear pathogenetic role to date (75). Finally, the timing of IgG humoral immune response generation and its quality, dependent on both Fab-associated (epitope repertoire diversity, antibody affinity maturation, neutralizing potential) and Fc-associated functions (antibody isotype class switching along with FcR affinity binding and associated Fc phagocytic functions), were all critical factors that dictated disease progression and/or resolution $(76,77)$.

\section{Deregulated Interferon Responses}

The first phenomenon observed in the aberrant host immune response against SARS-CoV-2 is an impaired induction of both type I and type III (IFN- $\lambda$ ) IFNs. Type I IFN levels tend to decline rapidly, whereas that of IFN- $\lambda$ persist longer. Despite the limited ability of COVID-19 patients to produce IFNs, especially at the initial stage of the disease, they robustly express proinflammatory cytokines that can be maintained in the serum at high concentrations for a prolonged period of time. Delayed but persistent type I IFN responses may drive the excessive lung infiltration by monocytes/macrophages and neutrophils, as it has been shown for other CoVs (78). These cells can, in turn, produce high amounts of pro-inflammatory cytokines like TNF $\alpha$, IL-6, IL-1 $\beta$, as well as chemokines, that amplify the recruitment of immune cells on site and propagate the inflammatory response, thus contributing to cytokine deregulation (79). Findings from different patients suggest that some aspects of the disease, like the myopathy and the Perniolike lesions (or COVID toes), may result from a type I interferonopathy. It is appreciated now that an initial robust type I IFN response can result in faster and better clearance of SARS-CoV-2, while a muted response, leads to viral persistence and severe disease $(11,80)$. In support of the above, patients with COVID-19 treated early with IFN- $\alpha 2 b$ exhibit reduced inhospital mortality, whereas late application of therapy leads to increased mortality and delayed recovery. This observation highlights the crucial importance regarding the timing of IFN production in COVID-19 $(44,81)$.

\section{Cytokine Deregulation}

The diminished interferon response leads to an ineffective viral clearance and a deregulated activation of the adaptive immunity, which in turn results in enhanced activation of the innate immunity as a compensatory mechanism. This condition further results in an aggressive uncontrolled inflammatory response and the release of a large amount of pro-inflammatory cytokines and chemokines which cause damage in different organs/systems. Circulating IL-6, IL-18, IFN- $\gamma$, IL-15, TNF $\alpha$, IL-1 $\alpha$, IL-1 $\beta$, IL-2, G-CSF, IP-10 (or CXCL10), MCP1 (or CCL2), MCP3 (CCL7) and MIP-1 $\alpha$ (CCL3) are over-expressed in patients with moderate or severe COVID-19 (82). Studies have suggested a direct correlation between cytokine levels and lung injury, multiple organ failure, and an unfavorable prognosis. So far, no specific cytokine or cell has been identified as the driver of this process (83). This state has been referred, by some researchers, as "cytokine storm". However, this term has been queried because the hyper-inflammatory phenotype seen in severe COVID-19 is different from other hyper-inflammatory conditions, since the cytokine levels are not particularly exacerbated (84).

Different inherent or acquired conditions including gender differences (female $v s$ male) (85), inflammaging and other preexisting conditions such as baseline immunosuppression, immune exhaustion and immunosenescence are additional factors which could affect this delicate balance $(56,86,87)$. In elderly patients, inflammaging - a chronic low-grade sterile inflammation characterized by high baseline serum levels of CRP and cytokines like IL-6 and IL-8 (88)- along with the inflammation induced by SARS-CoV-2, can drive the expression of specific transmembrane molecules. Such molecules like the Major histocompatibility complex class I chain-related protein A (MICA) and B (MICB) are also expressed by senescent cells normally found on the respiratory epithelium. As a result, highly-differentiated senescent T-cells with an NK-like phenotype that express NK-receptors (NKG2D) are attrackted leading to the subsequent destruction of the epithelial cells (89).

Although a clear distinction between factors that drive the aberrant cytokine expression, and factors that are the result of this deregulation is in the majority of cases difficult to be pointed out, we will try to address these two parameters separately.

\section{DRIVERS OF CYTOKINE DEREGULATION}

\section{Immune-Mediators}

As presented earlier in this review, the cytokine over-expression is a result of a deregulated innate and adaptive immune response. In severe COVID-19 macrophages seem to play a central role through the excessive production of pro-inflammatory cytokines and chemokines (90). Macrophages from patients with severe COVID-19 exhibit lower expression of apolipoproteins which correlates with a pro-inflammatory phenotype (91). Resident pro-fibrotic (SPP1 $\left.1^{\text {high }}\right)$ and inflammatory activated $\left(\mathrm{FABP} 4^{+}\right)$ macrophage populations are dominant in the lungs of patients with severe COVID-19 (92). In addition, activated monocytes/ macrophages can express tissue factor (TF) and promote thrombosis (93). Moreover, peripheral blood neutrophils of 
severe COVID-19 patients show increased numbers and marked hyper-responsiveness, as attested by the enhanced degranulation, neutrophil extracellular traps (NETs) release and pro-inflammatory cytokine production (94). An increased neutrophils/lymphocytes ratio has been associated with a higher morbidity and mortality of COVID-19 (95). Mast cell activation and the release of various vasoconstrictive or inflammatory mediators, like histamine, tryptase, chymase, IL-1 $\beta$, IL-6, TNF$\alpha$, CCL2, GM-CSF and CXCL10, contribute to local inflammation, tissue destruction, and cytokine imbalance (96). Additionally, the decreased numbers of $\mathrm{CD} 4{ }^{+} \mathrm{T}$-cells observed in severe COVID-19 can contribute to hyper-inflammation via the impaired regulatory mechanisms of the inflammatory process or via impaired adaptive T- and B- cell responses $(23,97)$. Finally, increased IL-17 production by Th17 cells in COVID-19 patients has broad pro-inflammatory effects through the upregulation of pro-inflammatory cytokines like G-CSF, IL-1 $\beta$, IL-6, TNF $\alpha$, as well as chemokines like MIP2A, IL-8, IP10, MIP3A, and matrix metalloproteinases (98).

\section{Cellular Stress-Response Mediators}

\section{Cellular Senescence}

Cellular senescence is a stress response against a plethora of cellular insults, including effects of infectious agents through mechanisms of DNA damage, cell fusion and ER stress (31). It is characterized by 4 interconnected hallmarks of: cell cycle arrest, macromolecular damage, altered metabolism and proinflammatory features, called the senescence-associated secretory phenotype (SASP) (99). Such a response is activated upon accumulation of sub-lethal cellular damage that cannot be resolved by the physiological repair mechanisms and acts as fail-safe to prevent propagation of damage - viral dissemination, in the case of viral illnesses (100)- in both cellular and tissue level (101). Thus, its homeostatic role is widely accepted in physiology and pathophysiology, with its role in infectious diseases being still ill-defined (102). In some instances, cellular senescence is beneficial to the host since it obstructs viral replication and damage, while in others, it appears to facilitate viral-induced pathology $(102,103)$. Such a binary mode of action characterizes many facets of cellular senescence. It is likely that within this context, the fitness of the host (102), the timing of initiation of cellular senescence program and its duration, all together play key roles in the outcome of viral diseases like COVID-19. Within this context, we have recently showed that SARS-CoV-2 triggers senescence with various clinical and epidemiological implications, including quasispecies generation (31).

The above findings are of high clinical translational potential, as drugs specifically targeting the elimination of senescent cells, could alter disease clinical course once established, or even be used prophylactically prior to viral exposure. Nonetheless, large clinical trials are necessary for the establishment of the type and timing of such treatment strategies.

\section{Uncontrolled Inflammatory Cell Death - PANoptosis}

SARS-CoV-2 can trigger different types of cell death (Figure 5) (33, 104-107). Uncontrolled inflammasome activation and excessive pyroptosis, which is suggested to be the main "death mode" observed in COVID-19, can result in an hyperinflammatory condition leading to severe disease, particularly in elderly patients (105). NLRP3, the major component of inflammasome, is already activated in older people as well as different pathological states that also serve as risk factors for severe COVID-19, including obesity, hypertension, cardiovascular disease, COPD and diabetes mellitus (108). Given that the threshold of inflammasome activation is very low in such patients, SARS-CoV-2 infection offers a significant additive effect predisposing them to uncontrolled inflammasome activation and subsequent hyper-inflammatory response (109). Interestingly, quite recently, a novel type of programmed inflammatory cell death called PANoptosis, has been described in murine models of COVID-19 exhibiting hypercytokinemia, similar to that described in severe COVID-19 in humans. The term PANoptosis is used to describe the simultaneous activation of Pyroptosis, Apoptosis and Necroptosis in the same cell, leading to its inflammatory death (34). More specifically, increased TNF $\alpha / \mathrm{IFN}-\gamma$ signaling has been shown to activate the STAT1/IRF1/iNOs/NO pathway, which in turn leads to the formation of a cytoplasmic multimeric protein complex called PANoptosome. PANoptosome then acts as a molecular scaffold for the assembly and activation of effector molecules like RIPK1/RIPK3/FADD/caspase 8, subsequently followed by the contemporaneous activation of pyroptosis via GSDME, apoptosis via Caspase $3 / 7$ and necroptosis via MLKL. This inflammatory cell death further enhances the inflammatory state by the release of PAMPs, DAMPs and other proinflammatory molecules (34).

\section{CONSEQUENCES OF CYTOKINE DEREGULATION}

The above-described cytokine deregulation, augmented by the deregulated Renin-Angiotensin-Aldosterone System (RAAS) shown in Figure 2, has a series of immunological and physiological effects that eventually lead to multi-organ damage, and if not treated, to multi-organ failure, ARDS and death (Figure 6) $(87,110-112)$.

\section{Immune Sequelae}

\section{Deregulated Innate Immunity}

Decreased HLA-DR and increased PD-L1 expression has been documented in COVID-19 monocytes (94). These findings suggest exhaustion of these cells and probably impaired antigen presentation to naive T cells (113). DCs in COVID-19 patients are reduced, with impaired maturation and function, suggesting also impaired antigen presentation and $\mathrm{T}$ cell activation (114). Patients with severe disease display the highest expression of PD-L1 and the lowest expression of the maturation marker CD80 on DCs (94). Activated NK cells expressing KIRs and CD16 are significantly decreased in COVID-19 patients, implying either impaired maturation or increased migration into the target tissues (115). They also 


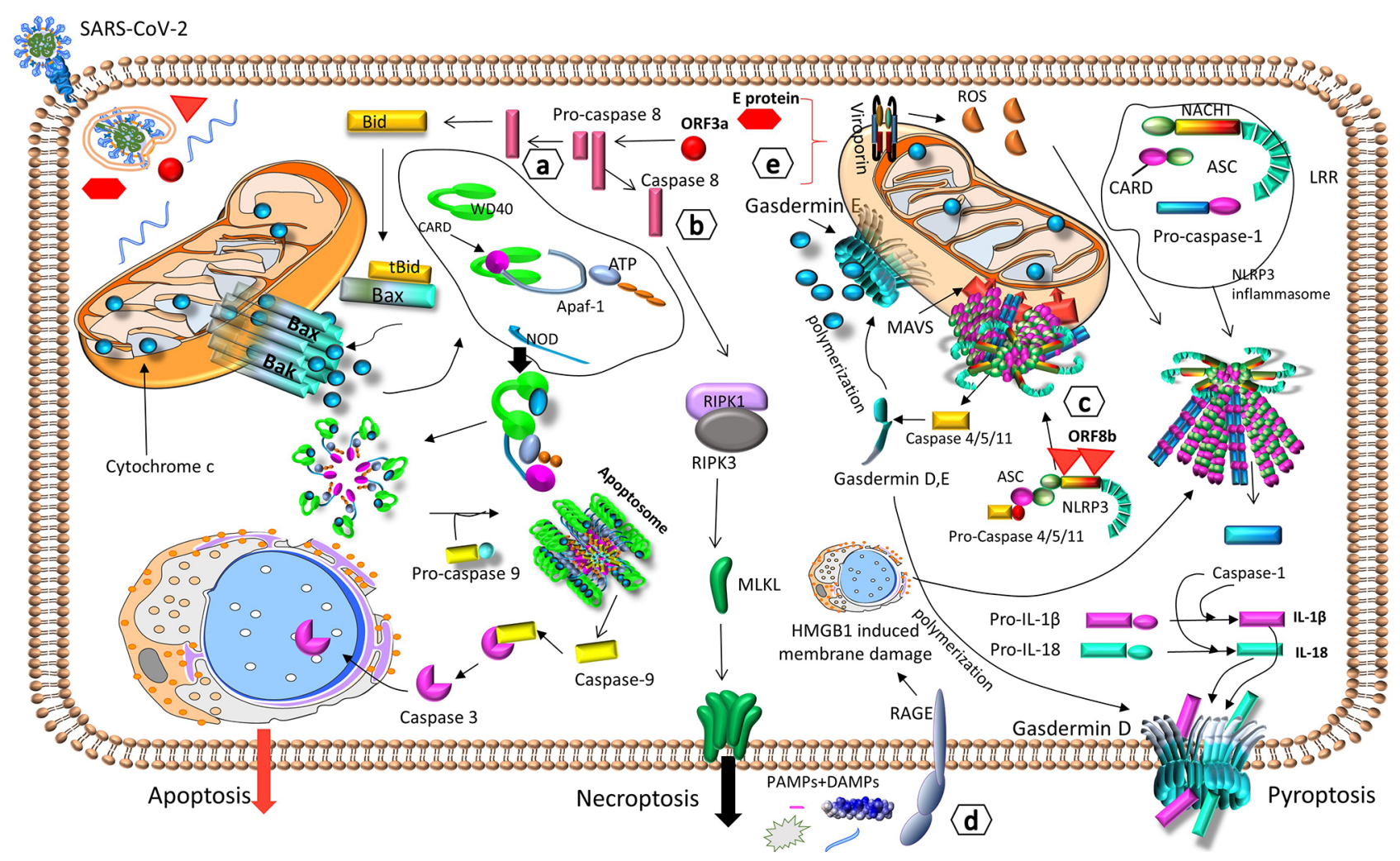

FIGURE 5 | SARS-CoV-2 can trigger different types of cell death. SARS-CoV-2 induces cell death and destruction of target cells via a) apoptosis, through caspase 8-BID/tBID-cytochrome c-caspase 9 (104), b) necroptosis, through caspase 8-RIPK1-RIPK3-MLKL (33), c) pyroptosis, through NLRP3-mediated inflammasome activation and gasdermin D - caspases-1, $-4,-5,-11$ (105). All modes of cellular death result in the destruction of infected cells and the release of PAMPs, DAMPs, $\mathrm{IL}-1 \beta$ and IL-18, which activate the innate immune response $(33,104,105)$, d) PAMPs and DAMPs from damaged cells, can also be detected by the receptor of RAGE, which triggers HMGB1-induced membrane damage, NLRP3-mediated inflammasome activation, and pyroptosis (106). e) During intracellular viral replication, the viral proteins ORF3a and E, form viroporins, that augment ROS production, NLRP3-mediated inflammasome activation, and pyroptosis (107). Apaf-1, apoptotic protease activating factor 1; ASC, apoptosis-associated speck-like protein containing a CARD; ATP, adenosine triphosphate; Bac, Bcl-2 homologous antagonist/ killer; Bax, Bcl-2-associated X protein; BID/tBID, BH3-interacting domain death agonist/truncated BID; CARD, caspase activation and recruitment domain; DAMPs, damage-associated molecular patterns; HMGB1, high mobility group box 1; IL, interleukin; LRR, leucine-rich repeat; MAVS, mitochondrial antiviral-signaling protein; MLKL, Mixed lineage kinase domain like; NACHT, NACHT domain; NLRP3, NOD-Like Receptor family pyrin domain containing 3; NOD, Nucleotide-binding Oligomerization Domain; PAMPs, pathogen-associated molecular patterns; RAGE, receptor of advanced glycation end products; RIPK, Receptor-interacting serine/ threonine-protein kinase; ROS, reactive oxygen species; WD40, WD40 domain.

correlate inversely with IL-6 plasma concentrations (116). Moreover, NK cells also show signs of exhaustion, with increased expression of the inhibitory CD94-NKG2A receptor heterodimer and decreased expression of CD107a, IFN- $\gamma$, IL-2 and granzyme B (117). Additionally, a low eosinophil count has been correlated to a worse prognosis in COVID-19 patients (118). Finally, increased numbers of myeloid-derived suppressor cells (MDSCs) - pathologically activated monocytes and neutrophils with potent immunosuppressive activity - have been detected in COVID-19 patients, with their number and activity correlating to disease severity (119-122). Such MDSCs have been shown to exhibit enhanced immunosuppressive activity by suppressing T-cell proliferation and function, as well as increased IFN- $\gamma$ and TNF-a production, probably contributing to a form of immune-paralysis observed in COVID-19 patients (119-121). Interestingly, during the convalescent phase of the disease, the numbers of MDSCs decline, but still remain increased in patients with severe COVID-19 in comparison to patients with mild disease (at least during the initial phase of convalescence) (119).

\section{Deregulated Adaptive Immunity \\ T-Cells}

$\mathrm{CD}^{+}$and $\mathrm{CD}^{+}$lymphopenia is commonly found in COVID-19 patients, resulting possibly either from direct cytotoxic effects of the virus, or from enhanced T-cell apoptosis due to the dysregulated cytokine milieu or metabolic disorders such as lactic acidemia (123).

Decreased T cell counts in severe COVID-19 have been associated with reduced $\mathrm{T}$ cell activation and function markers, including TCR subunits (CD3€, CD3 $\gamma, \mathrm{CD} 247$, TRAC, TRBC1), surface accessory molecules (CD4, CD8 $\alpha, \mathrm{CD} 8 \beta, \mathrm{CD} 2)$, T cell migration stimulators (DDP4), TCR signaling kinases (ZAP70, LCK, FYN) and MHC-II molecules (124). Peripheral CD8 ${ }^{+}$ 


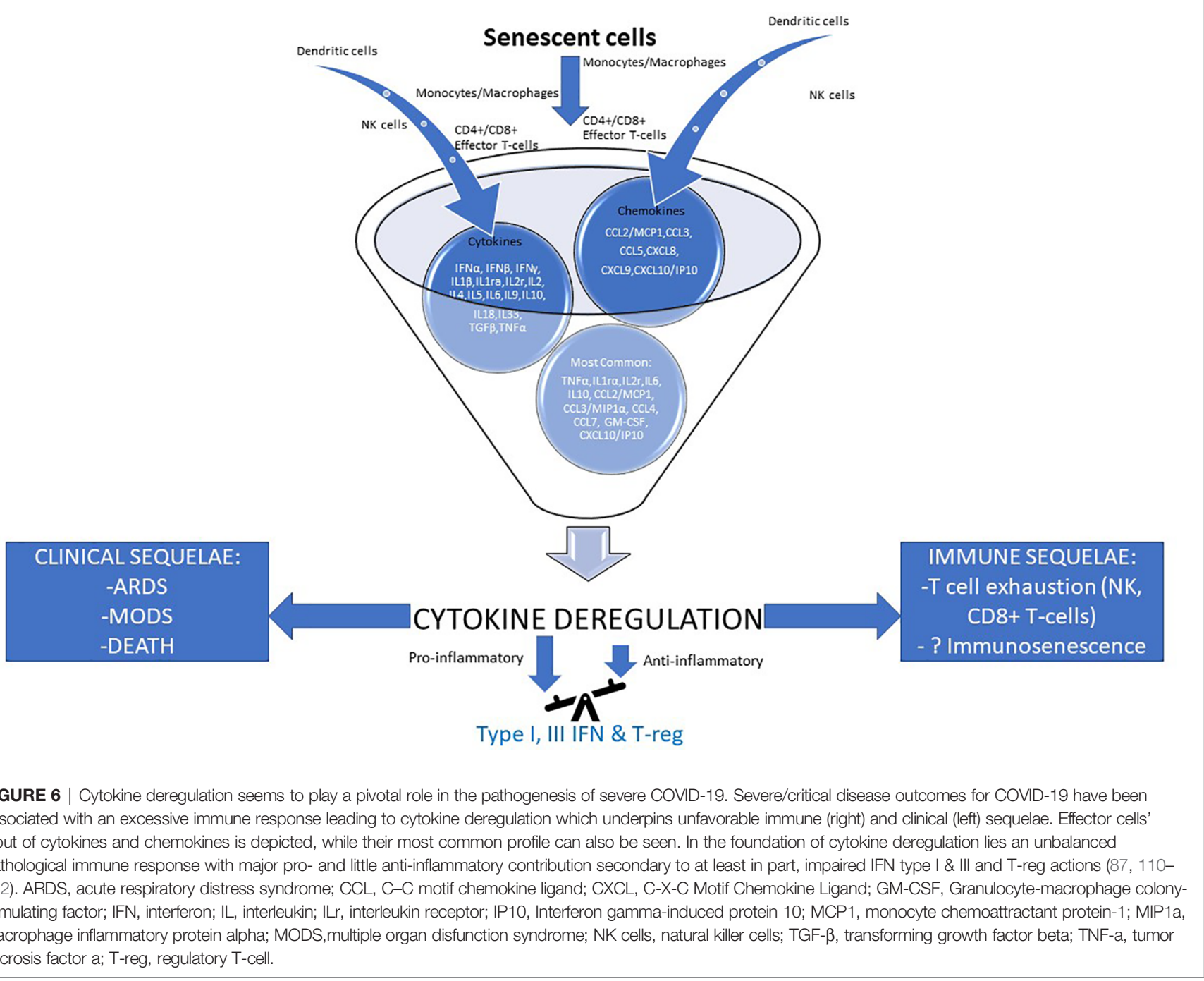

T cells also express high levels of exhaustion markers like PD1, TIM3 and CD57, suggesting a functional immune deficiency (125). In severe COVID-19, T cells also show features of an exhausted phenotype. These cells possibly not only lack markers of clonal expansion, but at the same time produce proinflammatory molecules (126). Thus, high levels of IL-1a and TNF $\alpha$ promote Th17 responses, increased vascular permeability and leakage. In turn, Th17 cells produce IL-17, GM-CSF, IL-21 and IL-22 (126). IL-17 has broad chemotactic effects through the upregulation of chemokines such as MIP2A, IL-8, IP10 and MIP3A (127).

Surprisingly, a marked plasma increase of typical Th2 cytokines, including IL-4, IL-10, and IL-13 has been observed in some severe COVID-19 patients. This observation could indicate that the activation of immune system in some severe cases, is not Th1-restricted but possess a much broader activation, involving all cells, similarly to what occurs during bacterial sepsis. Such a condition can lead in a form of immunoparalysis $(126,128)$.
FoxP3 $^{+}$Tregs are also elevated in several severe COVID-19 patients. It appears that severe COVID-19 entails a striking induction of Treg activation markers including FoxP3, KLRG1 and PD1 and a reduction of CD45RA, a marker of naïve Tregs. Moreover, severe COVID-19 induces the expression of Tbet that preferentially controls Th1 responses and downregulates the inflammatory cytokines TNF $\alpha$, IL- $1 \beta$. These changes suggest that Tregs in severe COVID-19 are shaped towards a supersuppressive phenotype equivalent to that observed in tumor Tregs (129).

\section{B-Cells}

Analyses of circulating B cells in patients with severe COVID-19 have shown an expansion of oligoclonal plasmablasts and reduced frequency of memory $B$ cells $(47,130)$. The antibody sequences of the largest B cell clones isolated from these patients have variable levels of somatic hyper-mutations and $\mathrm{VH}$ gene usage, indicative, as anticipated, of a polyclonal $\mathrm{B}$ cell response (130). Many COVID-19 patients possess neutralizing antibodies 
minimally mutated, suggesting a limited affinity maturation and, consequently, low binding affinity towards SARS-CoV-2 (131). This disparate antibody response might indicate a failure to develop robust long-lasting protective humoral responses against SARS-CoV-2 in some patients (132).

Early antibody responses against the spike protein have been associated with a favorable outcome, while early responses against the viral nucleocapsid with poor clinical outcomes (133). Detailed analysis of the antibody subtypes has revealed elevated IgG1 antibody production with a significantly increased Fc afucosylation. Afucosylated antibodies possess a much higher affinity for the FcyRIIIa receptor, triggering NK cell activation, the production of pro-inflammatory cytokines from monocytes/ macrophages, and the cytotoxic effector cell activities provided by cells bearing FcrRIIIa receptor (134). At the same time, afucosylated antibodies against SARS-CoV-2, might contribute to antibody-dependent enhancement of viral infectivity by promoting viral internalization in different cells expressing Fc $\gamma$ receptor, as it has been shown in animal studies (135).

\section{Disease Sequelae}

\section{Endothelial Activation and Endothelitis}

The high levels of circulating pro-inflammatory cytokines seen in severe COVID-19 are associated with local and systemic endothelial dysfunction and injury. IL- 6 and TNF $\alpha$ can increase vascular permeability and activate the endothelium (24). In turn, endothelial activation leads to increased TF expression, downregulation of thrombomodulin expression and loss of heparin sulfate - all protective mechanisms against thrombosis (136). Direct endothelial cell infection by SARS-CoV-2 and subsequent endothelitis can lead to increased vascular permeability, platelet activation, enhanced thrombin generation and decreased fibrinolysis, contributing to a hypercoagulable state (137, 138). Moreover, SARS-CoV-2 has been shown to directly disrupt the endothelial barrier by altering the surface expression of VCAM1 and the tight junction scaffold proteins ZO-1 and ICAM1, resulting in both chemotaxis and extravasation of inflammatory cells in the perivascular space (139). In COVID-19 patients, the perivascular space around the damaged endothelium is infiltrated by increased numbers of $\mathrm{CD}^{+}$and $\mathrm{CD} 4^{+} \mathrm{T}$-lymphocytesand the process of angiogenesis is skewed towards an intussusceptive pattern of vessel formation (140). Moreover, cytokine deregulation can lead to blood-brain-barrier disruption, hence enhancing the entrance of cytokines, or even SARS-CoV-2 into the central nervous system (CNS) (141). This mechanism has been proposed as the main event driving the entrance of the virus into the CNS and the intrathecal production of anti-SARS-CoV-2 antibodies in the cerebrospinal fluid, leading to neurologic damage through either the complement or macrophages (142).

It is hypothesised that the endothelial cell dysfunction, when it occurs in COVID-19, characterises the more severe forms of the disease, underpinning the associated complications including the capillary leak syndrome and thrombosis (143). Such a dysfunction can be caused by endothelial cell inflammation, as shown in autopsy studies $(144,145)$ which can either reflect direct viral cytotoxic effects or a bystander/indirect effect of hyper-cytokinemia (146). Although the latter is generally well accepted in the literature, direct endothelial cell infection by SARS-CoV-2 remains still elusive.

\section{Immunothrombosis}

The coagulation system and the immune system are two coworkers, complementing each other to provide host defense and limit the dissemination of invading pathogens (147). COVID-19 is characterized by an elevated risk for thrombosis both in macro- and micro-circulation, contributing substantially to morbidity and mortality (148). Many studies suggest that SARS-CoV-2, through various mechanisms, has the ability to affect different cells or systems in both the immune and the coagulation arm of the host defense, amplifying lung or systemic inflammation and subsequently leading to tissue damage and thrombosis in a process known as immunothrombosis (149, $150)$. The main contributors to this phenomenon -as depicted in Table 2 (93, 151-173) and Figure 7 (149, 161, 163, 174-176) are: megakaryocyte dyshomeostasis, platelet activation, Neutrophil Extracellular Traps (NETs) formation, complement hyper-activation and coagulation cascade activation as well as endothelial activation/inflammation as described above (149, 150, 163).

\section{Autoantibodies and Autoimmunity}

Some researchers have questioned whether the manifestations of COVID-19 are a mere result of the infection per se or a result of autoimmune reactions initiated or exacerbated by the infection (177). Viral infections not only share common immune responses with autoimmune diseases (ADs), but also they can break immune tolerance and cause autoimmunity by a variety of mechanisms such as molecular mimicry, bystander activation and epitope spreading (178-180). The reduction of regulatory $\mathrm{T}$ cellsand the increased number of Th17 and cytotoxic $\mathrm{CD}^{+} \mathrm{T}$-cells that are observed in severe COVID-19 (as described above), have also been described in several autoinflammatory/autoimmune diseases $(181,182)$. Additionally, lymphopenia and neutrophilia, as well as extrafollicular B-cell activation that have been observed mainly in severe COVID-19, also consist a common feature between COVID-19 and some ADs $(183,184)$. Moreover, cytokine deregulation and immune hyper-stimulation with some features of immunoparalysis can break tolerance and trigger the activation of auto-reactive $\mathrm{T}$ - and B-cells in autoimmune susceptible individuals in an antigen-independent manner, a phenomenon known as bystander activation $(185,186)$. Additionally, peptide sharing analyses have identified a massive hexapeptide and heptapeptide sharing between SARS-CoV-2 protein $\mathrm{S}$ and human proteins, with more than 460 such examples $(187,188)$. It has therefore been suggested that antibodies against SARS-CoV2 peptides or against the viral S protein, could boost immune crossreactions against human proteins like the pulmonary surfactant, the brainstem respiratory pacemaker transglutaminases 2 and 3, mitochondrial proteins, nuclear antigens etc., thus leading to autoimmune tissue destruction (189). Finally, it has been proposed that the enhanced NETosis observed in COVID-19 could also drive autoimmune phenomena, since excessive NETosis has been implicated in the pathophysiology of other autoimmune diseases $(186,190)$. Interestingly, enhanced 
TABLE 2 | Proposed mechanisms contributing to the (immuno)thrombosis observed in COVID-19 patients.

\section{Effector cells/ molecules}
Platelets $\quad$ Platelets from COVID-19 patients exhibit altered gene expression, increased activation and formation of platelet-leukocyte complexes, $\quad$ (93, 154, and increased release of platelet-derived proinflammatory and prothrombotic microparticles
Platelets from COVID-19 patients release larger amounts of proinflammatory cytokines, chemokines and growth factors in comparison to healthy controls upon stimulation
Platelets contribute to increased fibrinogen, VWF and FX in COVID-19 patients
(93, 154

NETS

NET number, as well as their contents, like myeloperoxidase-DNA, and citrullinated histone H3 are significantly increased in COVID-19

$(157,158)$ patients, correlate with disease severity, and may return to normal in convalescent patients

NETs are found in pulmonary microthrombi in patients who died from COVID-19 ARDS

NETs provide a platform for expression-activation of coagulation factors such as TF and FXII

NETs interact with VWF released by endothelial cells and platelets, leading to platelet adhesion and fibrin formation

NET-derived histones and TF can induce endothelial cell activation and thrombogenicity

NET formation enhances thrombus stability and lytic resistance, while through the release of neutrophil elastase, degrades TFPI and thrombomodulin and thus dampens anticoagulation

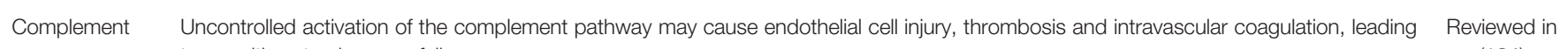
to a multi-systemic organ failure

C4d and C5b-C9 deposits in lung and skin microvasculature are co-localized with viral spike glycoproteins

Increased levels of complement system proteins are associated with enhanced activation of neutrophils and subsequent release of

The serum levels of C5a and C5b-9 are elevated and correlate to disease severity and vWF levels

C3 inhibition downregulates procoagulant and fibrinolytic responses and attenuates NETosis in COVID-19 patients $(167)$

Complement activation correlates strongly with CRP levels, prothrombin time and D-Dimers

Coagulation TF expressed either by the activated endothelium or by neutrophils, macrophages and platelets, can activate the extrinsic coagulation pathway NETs and complement can activate the intrinsic coagulation pathway

Complement hyper-activation and several pro-inflammatory or regulatory cytokines, including IL-1 $\beta, I L-2, I L-6, I F N-\gamma$ and TNF- $\alpha$ promote thrombosis through the endothelial activation, pro-coagulant NETosis, increased release of ultra-large VWF multimers, increased production of FVII/FVIla, TF and PAl-1, as well as increased generation of thrombin

Anti-phospholipid autoantibodies detected in COVID-19 patients are associated with NETosis and have the ability to accelerate venous thrombosis in mice

Angiotensin signaling through AT1 can systemically enhance inflammation and thrombosis, and through the activation of the Kinin-
Kallikrein system, it can induce systemic fibrinolysis and result in a DIC-like condition
Activation of the Kinin-Kallikrein system and the complement cascade are associated with increased D-Dimers and disease severity in
COVID-19 patients

ARDS, Acute respiratory distress syndrome; AT1, angiotensin II receptor 1; DIC, disseminated intravascular coagulation; FVII, coagulation factor VII; FXa, coagulation factor Xa; FXII, coagulation factor XII; IFN- $\gamma$, interferon gamma; IFN-I, interferon I; IL, interleukin; NET, Nuclear Extracellular Trap; NETosis, production and release of NETs; PAI-1, plasminogen activator inhibitor 1; PF4, platelet factor 5; RANTES, Regulated upon Activation; Normal T Cell Expressed and Presumably Secreted; TF, tissue factor; TFPI, tissue factor pathway inhibitor; TNF-a, tissue necrosis factor a; VWF, von Willebrand factor.

expression and circulation of autoantigens like MPO or PRTN3 has also been observed in COVID-19 patients, and the levels of expression of some of these autoantigens correlate with disease severity (191).

In COVID-19 patients, a variety of autoimmune diseases/ phenomena have been described, reflecting the overall aberrant immune activation observed in these patients:
1) Different autoantibodies have been detected in many COVID-19 patients with no previous autoimmune rheumatic disease, including antinuclear antibodies, p-ANCA, c-ANCA, anti-CCP, anti-RNP, anti-centromere, Rheumatoid Factors, antitopoisomerase I and anti-prothrombin, with no, so far, clear clinical significance. Interestingly, some of these antibodies correlate with high levels of CRP and more severe disease. 


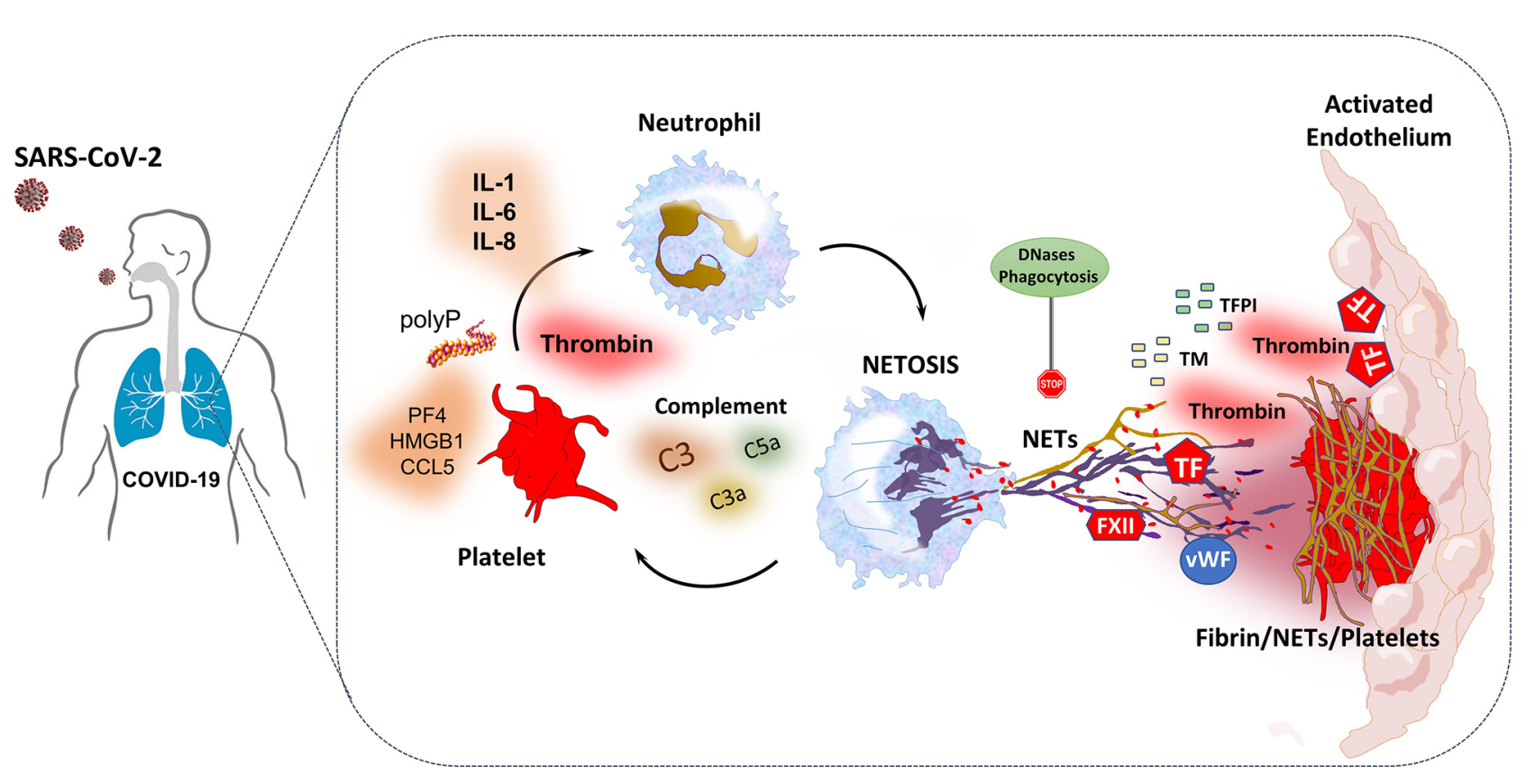

FIGURE 7 | SARS-CoV-2-triggered NETs induce thromboinflammation through interactions with complement system, platelets and the coagulation cascade (161, 163). NETs provide a platform for expression-activation of coagulation factors such as TF and FXII. They also interact with WWF released by endothelial cells and platelets, leading to platelet adhesion and fibrin formation (174). Additionally, NET-derived histones and TF can induce endothelial cell activation and thrombogenicity. Furthermore, NET formation also enhances thrombus stability and Iytic resistance, while through the release of neutrophil elastase, degrades TFPI and thrombomodulin and thus dampens anticoagulation (174). Probably, in COVID-19, increased levels of platelet-derived thrombin and factors such as polyphosphate (polyP), high mobility group box 1 (HMGB1), PF4, RANTES, as well as complement and IL-1, IL-6 and IL-8 can trigger NETosis, which in turn activates platelets creating a feedback loop (174, 175). To the contrary, excessive NET formation is homeostatically regulated by anti-inflammatory mechanisms such as NET degradation by DNases, and phagocytic removal by macrophages, thus NET levels may normalize in convalescent patients (163, 174, 176). All the above suggest that the interplay between complement, platelets and NETs may play a central role in the immunothrombosis and ARDS observed in COVID-19 (161, 163, 176). ARDS, acute respiratory distress syndrome; FXII, coagulation factor XII; IL, interleukin; NET, neutrophil extracellular trap; PF4, platelet factor 4; RANTES, Regulated upon Activation, Normal T Cell Expressed and Presumably Secreted; TF, tissue factor; TFPI, tissue factor pathway inhibitor; vWF, von Willebrand factor.

However, whether these antibodies are "functional" and have an etiopathogenic relation to COVID-19 manifestations or are just an epiphenomenon, for the majority of cases, remains to be proven $(180,192,193)$.

2) Autoimmune thrombocytopenia or hemolytic anemia with the concurrent detection of warm autoantibodies or coldagglutinins have also been described, and some of these cases have been successfully treated with IVIG (189). As for the hemolytic anemia, molecular mimicry is probably the main pathogenetic mechanism, since for example, the erythrocyte protein Ankyrin-1 shares a common pentamer with SARSCoV-2 spike protein (194). Interestingly, IgG3 which is associated with worse prognosis in COVID-19, is the only IgG subclass capable of forming cryoglobulins through Fc-Fc interactions (195). On the other hand, some cases of vaccination against SARS-CoV-2 have been associated with a prothrombotic immune thrombocytopenia (VIPIT) attributed to autoantibodies directed against PF4, a situation similar to Heparin-Induced Thrombocytopenia (HIT) (196).

3) Antiphospholipid syndrome or even catastrophic antiphospholipid syndrome with the involvement of at least 2 target-organs have also been described in COVID-19 patients.
Interestingly, not all 3 types of antiphospholipid antibodies (lupus anticoagulant and/or anticardiolipin and/or beta glycoprotein I) have not been detected in all cases. The levels of antiphospholipid autoantibodies correlated with the CRP levels in serum, D-dimer concentrations in plasma, platelet counts, absolute neutrophil counts, calprotectin in serum (marker of neutrophil activation), and myeloperoxidase-DNA complexes in serum (marker of NETs). Additionally, high levels of such antibodies are associated with more severe disease. However, antiphospholipid antibodies are not always accompanied by thrombosis and in such cases they can possibly be merely the result of the immune hyperactivation and prothrombotic state observed in these patients (171, 192, 197).

4) Some patients have developed different forms of vasculitis (small vessel, middle vessel, large vessel, IgA, cutaneous, CNS vasculitis etc.) in which the inflammation is not limited to the endothelium, but manifests as a peri- and pan-arteritis with immune complex depositions[Reviewed in $(186,198)]$. A more severe form of vasculitis is the Kawasaki-like disease (KD-like) or Multisystem Inflammatory Syndrome in children with COVID19. During the pandemic, a striking rise in $\mathrm{KD}$-like cases has 
been reported. This disease affects mainly children and targets preferentially the heart, the intestine, and the brain. The pathogenetic cause of this disease seems to be an autoimmune vasculitis, since different autoantibodies have been described in these patients, like antibodies against endoglin, MAP2K2 and members of the Casein Kinase Family, with a distinct inflammatory profile from that of COVID-19 cytokine deregulation (199).

5) Otherpatients have developed an acute inflammatory immune-mediated progressive poly-radiculoneuropathy presenting with tingling, weakness, autonomic dysfunction, and pain, resembling Guillain-Barre syndrome or its variant Miller-Fisher syndrome. Some of these patients have been successfully treated with IVIG or plasmapheresis (189).

6) Cases of inflammatory arthritis or spondyloarthropathy, usually 1-3 weeks after the infection have also been recorded (198).

7) Some COVID-19 patients have developed a new systemic connective tissue disease like Systemic Lupus Erythematosus (SLE). On the other hand, a flare of a preexisting autoimmune disease after COVID-19 has also been described (200-204).

8) Case reports of autoimmune myositis or glomerulonephritis, as well as autoimmune endocrinopathies (thyroiditis, Grave's disease, type I diabetes mellitus) have also been described in the context of COVID-19 [reviewed in $(186,198)$ ].

9) Some researchers also believe that anosmia (loss of smell) that develops in many COVID-19 patients (186), could also be an autoimmune phenomenon, since such olfactory disturbances have also been described in other autoimmune conditions (205).

10) Based on histopathological, radiological and serological similarities between COVID-19-related ARDS and acute exacerbation of connective tissue disease-induced interstitial lung disease, some researchers suggest that lung involvement in COVID-19 in predisposed patients might be a type of organspecific autoimmune reaction (206).

COVID-19 in patients already suffering from an AD - either clinically or subclinically - may be affected by this AD or the medications used for it and, to the contrary, may influence this $\mathrm{AD}$. On the other hand, patients without any $\mathrm{AD}$ face the danger of developing a new AD as a result of COVID-19 (207). Theoretically, patients with autoimmune diseases are at increased risk for infections and thus increased risk for COVID-19, due to deregulated adaptive immunity (cellular and/or humoral) (208). However, different studies addressing this issue have not clearly established such an increased risk $(189,209,210)$. To the contrary, some patients with prior autoimmune/autoinflammatory conditions infected with SARSCoV-2 have shown better outcomes, probably due to baseline immunomodulatory medications (211-213). For example, the use of TNF inhibitors has been associated with protection from severe COVID-19, while most of the disease-modifying antirheumatic drugs (DMARDS) do not seem to confer increased risk (214). On the other hand, patients treated with Rituximab or Secukinumab exhibit high concentrations of IL-6 and seem to have a worse prognosis. CD20 blockers, in particular, could impair B-cell function and therefore the production of neutralizing antibodies against SARS-CoV-2 (215). Chronic sulfasalazine use has also been associated with worse prognosis (216). Moreover, it seems that co-administration of conventional synthetic DMARDSwith biologic treatmentsputs patients at increased risk for severe COVID-19 (217). Finally, chronic treatment with glucocorticoids has been associated with poorer outcomes (218).

Genes associated with genetic susceptibility for autoimmune diseases (like TLR7, MHC region, PTPN22, TYK2 and IL6R) are being assessed in an effort to explain heterogeneity in COVID-19 severity and organize treatment decisions in a personalized way, but the results are still inconclusive. For example, genetic variations in IL-6 signalling could affect both the presentation of COVID-19 and the response to an anti-IL6 treatment (68).

\section{DISCUSSION}

It has been more than 1,5 years now since the initial declaration of COVID-19 as a pandemic. During this time, a great amount of knowledge has been gathered as a result of intensive research from many labs and hospitals around the world. An important message coming out of these studies is that many of the detrimental effects of COVID-19 in end-organ damage/ pathology are caused by insults directly attributed to the virus per se, but are also secondary to the immune deregulation (219). In this review, we attempted to summarize in a stepwise approach, the key pathophysiological processes that take place from viral inhalation to disease establishment, with emphasis on the immunopathology of COVID-19 (ranging from immunity to autoimmunity) and its heterogenous clinical outcomes. Intensive ongoing research all over the world, makes the need for continuous update of the acquired knowledge more than essential since new concepts constantly arise (for example PANoptosis or cellular senescence as features of COVID-19 pathobiology). Figure $\mathbf{8}$ depicts the critical steps for viral clearance or alternatively for viral persistence and aberrant/ sustained immune responses resulting in severe disease and/ or death.

Many researchers nowadays suggest, that, the deregulated immune response against SARS-CoV-2, as it is presented in this review, has some characteristic features of autoinflammation and autoimmunity and could therefore be used as a diseasemodel for this cluster of diseases of unknown etiology (192). A single virus - SARS-CoV-2 - has been shown to possess the capability to drive such a robust hyper-inflammatory immune response that even self-tolerance can be disrupted. As a consequence, and probably through other mechanisms like molecular mimicry, autoantibodies can be produced and result in different autoimmune phenomena and end-organ damage (220). Many researchers believe that the main manifestations of COVID-19 might be attributed to such autoimmune phenomena and not to the infection per se. For example the time needed for the full panel of symptoms to arise (1-2 weeks), coincides with the time needed for the production of autoantibodies $(220,221)$. Persistence of these autoantibodies and/or the accompanying 


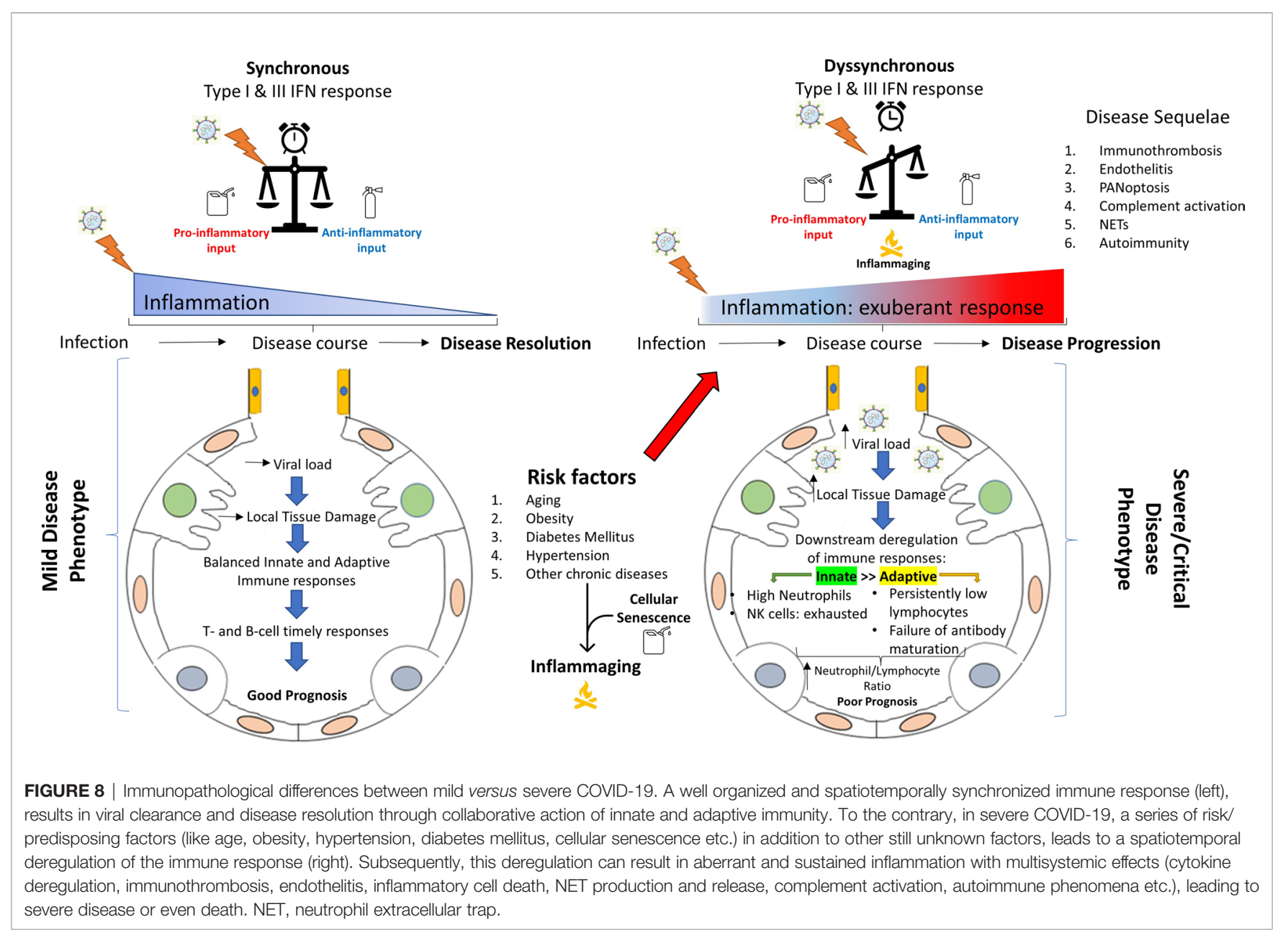

inflammation after the resolution of the acute phase of COVID19 has also been proposed as a possible mechanism leading to the so-called "long-COVID" (222-224). On the other hand, it is of interest, that, some of the main drugs used in patients hospitalized with COVID-19 (like corticosteroids, IL6 inhibitors, Jak inhibitors etc.) are immunosuppressive/ immunomodulatory drugs commonly used in autoimmune/ autoinflammatory diseases (225-229).

Many data that are now available strongly support the concept of COVID-19 being more than an infectious disease, with autoimmunity playing a pivotal role. However, many questions regarding COVID-19 and autoimmunity remain unanswered. On the one hand, complete understanding of the pathogenetic mechanisms underlying COVID-19, will give the opportunity for new, more targeted - thus more effective and less harmful - treatments. For example, blockade of inflammatory cell death (like pyroptosis and PANoptosis) could offer an alternative drug-target for COVID-19 and also help in the treatment of autoinflammatory diseases. Additionally, the temporal distribution of the different immunopathological mechanisms that drive COVID-19 pathogenesis, could help identify the right timing for specific therapies (like interferons). Moreover, if COVID-19 is not dealt with as a purely infectious disease, then other therapies could be implicated in its treatment (like anti-CD20 for the elimination of B-cells, IVIG or plasmapheresis for the neutralization or removal of pathogenic autoantibodies etc.). Detection of susceptibility genes/ polymorphisms could also help identify patients at risk for developing severe COVID-19 and autoimmune manifestations and guide treatment in a personalized manner.

On the other hand, it is not known whether all autoantibodies that are created in autantibody-naïve patients have an "active" role, or some of them represent an epiphenomenon. Additionally, neither what happens with these antibodies as time passes after the infection resolution, nor the mechanisms regulating their disappearance or preservation are known. Such knowledge could offer new insights into the treatment of autoimmune diseases. Moreover, since the cases of longCOVID have started to increase, it is essential to understand the pathogenetic mechanisms underlying this condition, to treat it in a more targeted-manner. Such knowledge could probably offer new ideas about the treatment of other chronic conditions like chronic pain or fibromyalgia.

Another promising concept regarding COVID-19 pathobiology and autoimmunity, is the concept of cellular senescence. It has been shown, that cellular senescence, 
and especially immunosenescence, is associated with the development of autoimmunity $(230,231)$. Could cellular senescence that preceds COVID-19 (e.g. in the elderly) or is triggered by the disease, put patients at higher risk for developing autoimmunity?

Lymphopenia is regarded as a hallmark of COVID-19 [according to the study and the disease severity, frequency can reach even $85 \%(232,233)]$, with redistribution to sites of active infection and enhanced destruction within the context of cytokinemia being proposed mechanisms. Yet the exact aetiology behind low lymphocyte count is still unknown as well as whether direct SARS-CoV-2 tropism to such cells exists (232). Additionally, studies have demonstrated the presence of spike viral antigen in lymphocytes by immunohistochemistry, while isolation of viral RNA extends beyond lymphocytes to include almost all leukocyte types (234). As a result, leukocytes could be hypothesized to act as a trojan horse facilitating immune evasion and potential viral dissemination systemically. However, appropriate experiments are still lacking to support this notion. In line with that, the functional outcome of direct viral replication within leukocytes would need to be investigated and the fate of those cells to be determined. Could exhaustion of the infected cells take place or immunosenescence be triggered as a response? What is driving immune exhaustion in COVID-19 and what differences exist between mild and severely infected individuals? What is the role of immunosenescence in the establishment of the cytokine deregulation and how does it correlate with clinical outcomes? Does the degree of immunosenescence differ in mild $v s$ severe disease, and if so, how?

All the above are some questions that if answered, they would deepen our understanding of the immunological phenomena in COVID-19 and possibly widen our-currently limited-treatment options against it. Scientists are eagerly seeking for new therapeutic agents (235) and drug repurposing tailored to COVID-19 is actively being investigated (236). In the light of findings pinpointing cellular senescence as an important disease modulator, especially in high-risk populations (31, 237, 238), such efforts could be expanded to include experimental use of senolytic drugs as well. This group of medicines act either by apoptosis-induced elimination of senescent cells (senolytics) or inhibiting their SASP-mediated effects (senomorphics) (239). Irrespective of their mode of action, senolytic drugs have tremendous translational potential not only in age-related diseases but in the treatment of infectious diseases too (240). As a stress response triggered by viral infections, senescent cells become tangible targets for elimination with these drugs potentially altering disease course by disrupting viral replication within them and clearing their associated inflammatory properties. Their use, either upon disease establishment or even prophylactically in high-risk populations harbouring a high-burden of these cells, is promising (241). Nonetheless, as these cells are important to normal homeostasis and physiology $(99,101)$, their destruction comes at a fair cost. To illustrate the latter, the use of senolytics has been associated with reactivation of latent viral infections (242), systemic toxicity
(243) and aberrant wound healing (244). Formal studies and clinical trials to assess their clinical efficacy are required prior to their consideration as therapeutic agents. As cellular senescence has a bright and a dark side, depending, at least in part, on the duration of its effects (245), clarifying the specifics of the timing of their interventional use should be a priority.

Concurrently to human studies, a series of pre-clinical animal models (mainly non-human primates, ferrets, Syrian hamsters, and genetically modified mice) have also been used [reviewed in (246-248)]. Unfortunately, these disease-models do not mimic human disease in its entirety. One important difference between humans and animal models of COVID-19, is the fact that most of the animals develop only mild-moderate disease that is limited to the lungs. In most of these cases, the initial response to SARSCoV-2 consists of a local innate immune activation (macrophages, mononuclear cells, NK cells, neutrophils) in the lungs with the production of inflammatory cytokines like IFN- $\gamma$ and IL- 6 and in some cases with the additional help of residual lymphocytes - especially cytotoxic $\mathrm{CD} 8^{+} \mathrm{T}$-cells. Moreover, in some of these models, type I and III IFNs have been shown to play a protective role. However, in contrast to humans, no severe cytokine deregulation with robust hyper-cytokinemia (and their consequences) has been described, and the initial phase of immune activation is usually followed by a more antiinflammatory $2^{\text {nd }}$ phase and disease resolution. These observations can be attributed either to an "inherent weakness" of each animal model (e.g., lack of enough ACE2 receptors for the initial infection to take place at sufficient levels) or to the local immune responses developed in these animals, that manage to eliminate the virus and prevent systemic disease. Interestingly, this milder disease phenotype can be overridden with the use of older animals or use of a higher viral inoculum [reviewed in $(249,250)]$. This observation suggests that the immune system has finite "capacity" of dealing with an intruder, and this capacity might decline with age. Further studies in animal models of COVID-19 and interpretation of their results in the light of comparative immunology might give us some new information about the crucial initial immune response that could block SARS-CoV-2 on site without evolving into a severe systemic disease.

\section{AUTHOR CONTRIBUTIONS}

$\mathrm{AK}$ and $\mathrm{KB}$ wrote the review. PS, VG, PV and AT substantially contributed to the discussion of the content, reviewed and edited the manuscript before submission. Additionally, KB, PS and PV created the images presented in this manuscript. All authors contributed to the article and approved the submitted version.

\section{FUNDING}

This work was funded for open access publication fees by the Institute for Autoimmune Systemic and Neurological Diseases, Athens, Greece. VGG and AGT are financially supported by the 
National Public Investment Program of the Ministry of Development and Investment/General Secretariat for Research and Technology, in the framework of the Flagship Initiative to address SARS-CoV-2 (2020EE01300001).

\section{REFERENCES}

1. Wadman M, Couzin-Frankel J, Kaiser J, Matacic C. A Rampage Through the Body. Science (2020) 368(6489):356-60. doi: 10.1126/science.368.6489.356

2. Abebe EC, Dejenie TA, Shiferaw MY, Malik T. The Newly Emerged COVID-19 Disease: A Systemic Review. Virol J (2020) 17(1):96. doi: 10.1186/s12985-020-01363-5

3. Gerotziafas GT, Catalano M, Colgan MP, Pecsvarady Z, Wautrecht JC, Fazeli B, et al. Guidance for the Management of Patients With Vascular Disease or Cardiovascular Risk Factors and COVID-19: Position Paper From VAS-European Independent Foundation in Angiology/Vascular Medicine. Thromb Haemost (2020) 120(12):1597-628. doi: 10.1055/s0040-1715798

4. Nishiga M, Wang DW, Han Y, Lewis DB, Wu JC. COVID-19 and Cardiovascular Disease: From Basic Mechanisms to Clinical Perspectives. Nat Rev Cardiol (2020) 17(9):543-58. doi: 10.1038/s41569-020-0413-9

5. Terpos E, Ntanasis-Stathopoulos I, Elalamy I, Kastritis E, Sergentanis TN, Politou M, et al. Hematological Findings and Complications of COVID-19. Am J Hematol (2020) 95(7):834-47. doi: 10.1002/ajh.25829

6. Weibiao Zeng KQ, Ye M, Zheng L, Liu X, Hu S, Zhang W, et al. Gastrointestinal Symptoms Are Associated With Severity of Coronavirus Disease 2019: A Systematic Review and Meta-Analysis. Eur J Gastroenterol Hepatol (2021). doi: 10.1097/meg.0000000000002072

7. Zhong $\mathrm{P}, \mathrm{Xu}$ J, Yang D, Shen Y, Wang L, Feng Y, et al. COVID-19Associated Gastrointestinal and Liver Injury: Clinical Features and Potential Mechanisms. Signal Transduct Target Ther (2020) 5(1):256. doi: 10.1038/ s41392-020-00373-7

8. Nadim MK, Forni LG, Mehta RL, Connor MJ Jr, Liu KD, Ostermann M, et al. COVID-19-Associated Acute Kidney Injury: Consensus Report of the 25th Acute Disease Quality Initiative (ADQI) Workgroup. Nat Rev Nephrol (2020) 16(12):747-64. doi: 10.1038/s41581-020-00356-5

9. Iadecola C, Anrather J, Kamel H. Effects of COVID-19 on the Nervous System. Cell (2020) 183(1):16-27.e1. doi: 10.1016/j.cell.2020.08.028

10. Singh H, Kaur H, Singh K, Sen CK. Cutaneous Manifestations of COVID-19: A Systematic Review. Adv Wound Care (2021) 10(2):51-80. doi: 10.1089/ wound.2020.1309

11. Manzano GS, Woods JK, Amato AA. Covid-19-Associated Myopathy Caused by Type I Interferonopathy. N Engl J Med (2020) 383(24):238990. doi: 10.1056/NEJMc2031085

12. Leticia de Oliveira Toledo S, Sousa Nogueira L, das Gracas Carvalho M, Romana Alves Rios D, de Barros Pinheiro M. COVID-19: Review and Hematologic Impact. Clin Chim Acta (2020) 510:170-6. doi: 10.1016/ j.cca.2020.07.016

13. Jiang S, Hillyer C, Du L. Neutralizing Antibodies Against SARS-CoV-2 and Other Human Coronaviruses: (Trends in Immunology 41, 355-359; 2020). Trends Immunol (2020) 41(6):545. doi: 10.1016/j.it.2020.04.008

14. Shereen MA, Khan S, Kazmi A, Bashir N, Siddique R. COVID-19 Infection: Origin, Transmission, and Characteristics of Human Coronaviruses. J Adv Res (2020) 24:91-8. doi: 10.1016/j.jare.2020.03.005

15. Alanagreh L, Alzoughool F, Atoum M. The Human Coronavirus Disease COVID-19: Its Origin, Characteristics, and Insights Into Potential Drugs and Its Mechanisms. Pathogens (2020) 9(5):331. doi: 10.3390/ pathogens 9050331

16. Tu YF, Chien CS, Yarmishyn AA, Lin YY, Luo YH, Lin YT, et al. A Review of SARS-CoV-2 and the Ongoing Clinical Trials. Int J Mol Sci (2020) 21 (7):2657. doi: 10.3390/ijms21072657

17. Bar-On YM, Flamholz A, Phillips R, Milo R. SARS-CoV-2 (COVID-19) by the Numbers. eLife (2020) 9:e57309. doi: 10.7554/eLife.57309

18. Jiang S, Hillyer C, Du L. Neutralizing Antibodies Against SARS-CoV-2 and Other Human Coronaviruses. Trends Immunol (2020) 41(5):355-9. doi: 10.1016/j.it.2020.03.007

\section{ACKNOWLEDGMENTS}

We would like to thank Prof. Haralampos M. Moutsopoulos for his contribution in reviewing the manuscript before submission.

19. Hou YJ, Okuda K, Edwards CE, Martinez DR, Asakura T, Dinnon KH 3rd, et al. SARS-CoV-2 Reverse Genetics Reveals a Variable Infection Gradient in the Respiratory Tract. Cell (2020) 182(2):429-46.e14. doi: 10.1016/ j.cell.2020.05.042

20. Verdecchia P, Cavallini C, Spanevello A, Angeli F. The Pivotal Link Between ACE2 Deficiency and SARS-CoV-2 Infection. Eur J Intern Med (2020) 76:14-20. doi: 10.1016/j.ejim.2020.04.037

21. Zhao Y, Zhao Z, Wang Y, Zhou Y, Ma Y, Zuo W. Single-Cell RNA Expression Profiling of ACE2, the Receptor of SARS-CoV-2. Am J Respir Crit Care Med (2020) 202(5):756-9. doi: 10.1164/rccm.202001-0179LE

22. Gheblawi M, Wang K, Viveiros A, Nguyen Q, Zhong JC, Turner AJ, et al. Angiotensin-Converting Enzyme 2: SARS-CoV-2 Receptor and Regulator of the Renin-Angiotensin System: Celebrating the 20th Anniversary of the Discovery of ACE2. Circ Res (2020) 126(10):1456-74. doi: 10.1161/ CIRCRESAHA.120.317015

23. Henry BM, Vikse J, Benoit S, Favaloro EJ, Lippi G. Hyperinflammation and Derangement of Renin-Angiotensin-Aldosterone System in COVID-19: A Novel Hypothesis for Clinically Suspected Hypercoagulopathy and Microvascular Immunothrombosis. Clin Chim Acta (2020) 507:167-73. doi: 10.1016/j.cca.2020.04.027

24. Teuwen LA, Geldhof V, Pasut A, Carmeliet P. COVID-19: The Vasculature Unleashed. Nat Rev Immunol (2020) 20(7):389-91. doi: 10.1038/s41577020-0343-0

25. Kuba K, Imai Y, Penninger JM. Multiple Functions of AngiotensinConverting Enzyme 2 and Its Relevance in Cardiovascular Diseases. Circ J (2013) 77(2):301-8. doi: 10.1253/circj.CJ-12-1544

26. Bernstein KE, Khan Z, Giani JF, Cao DY, Bernstein EA, Shen XZ. Angiotensin-Converting Enzyme in Innate and Adaptive Immunity. Nat Rev Nephrol (2018) 14(5):325-36. doi: 10.1038/nrneph.2018.15

27. Pal R, Bhansali A. COVID-19, Diabetes Mellitus and ACE2: The Conundrum. Diabetes Res Clin Pract (2020) 162:108132. doi: 10.1016/ j.diabres.2020.108132

28. Tikellis C, Thomas MC. Angiotensin-Converting Enzyme 2 (ACE2) Is a Key Modulator of the Renin Angiotensin System in Health and Disease. Int $J$ Peptides (2012) 2012:256294. doi: 10.1155/2012/256294

29. Xie X, Chen J, Wang X, Zhang F, Liu Y. Age- and Gender-Related Difference of ACE2 Expression in Rat Lung. Life Sci (2006) 78(19):2166-71. doi: 10.1016/j.lfs.2006.09.028

30. Santos RAS, Sampaio WO, Alzamora AC, Motta-Santos D, Alenina N, Bader $\mathrm{M}$, et al. The ACE2/Angiotensin-(1-7)/MAS Axis of the Renin-Angiotensin System: Focus on Angiotensin-(1-7). Physiol Rev (2018) 98(1):505-53. doi: 10.1152/physrev.00023.2016

31. Evangelou K, Veroutis D, Foukas PG, Paschalaki K, Lagopati N, Dimitriou $\mathrm{M}$, et al. SARS-CoV-2 Infects Lung Epithelial Cells and Induces Senescence and an Inflammatory Response in Patients With Severe COVID-19. bioRxiv (2021). doi: 10.1101/2021.01.02.424917

32. Ferreira AC, Soares VC, de Azevedo-Quintanilha IG, Dias S, FintelmanRodrigues N, Sacramento CQ, et al. SARS-CoV-2 Engages Inflammasome and Pyroptosis in Human Primary Monocytes. Cell Death Discov (2021) 7 (1):43. doi: 10.1038/s41420-021-00428-w

33. Li S, Zhang Y, Guan Z, Li H, Ye M, Chen X, et al. SARS-CoV-2 Triggers Inflammatory Responses and Cell Death Through Caspase-8 Activation. Signal Transduct Target Ther (2020) 5(1):235. doi: 10.1038/s41392-02000334-0

34. Karki R, Sharma BR, Tuladhar S, Williams EP, Zalduondo L, Samir P, et al. Synergism of TNF-Alpha and IFN-Gamma Triggers Inflammatory Cell Death, Tissue Damage, and Mortality in SARS-CoV-2 Infection and Cytokine Shock Syndromes. Cell (2021) 184(1):149-68.e17. doi: 10.1016/ j.cell.2020.11.025

35. Amor S, Fernandez Blanco L, Baker D. Innate Immunity During SARSCoV-2: Evasion Strategies and Activation Trigger Hypoxia and Vascular 
Damage. Clin Exp Immunol (2020) 202(2):193-209. doi: 10.1111/cei.13523

36. Zhao Y, Kuang M, Li J, Zhu L, Jia Z, Guo X, et al. SARS-CoV-2 Spike Protein Interacts With and Activates TLR41. Cell Res (2021) 31(7):818-20. doi: 10.1038/s41422-021-00495-9

37. Kawai T, Akira S. The Roles of TLRs, RLRs and NLRs in Pathogen Recognition. Int Immunol (2009) 21(4):317-37. doi: 10.1093/intimm/ dxp017

38. Li G, Fan Y, Lai Y, Han T, Li Z, Zhou P, et al. Coronavirus Infections and Immune Responses. J Med Virol (2020) 92(4):424-32. doi: 10.1002/ jmv. 25685

39. Perry AK, Chen G, Zheng D, Tang H, Cheng G. The Host Type I Interferon Response to Viral and Bacterial Infections. Cell Res (2005) 15(6):407-22. doi: 10.1038/sj.cr.7290309

40. McNab F, Mayer-Barber K, Sher A, Wack A, O'Garra A. Type I Interferons in Infectious Disease. Nat Rev Immunol (2015) 15(2):87-103. doi: 10.1038/ nri3787

41. Sa Ribero M, Jouvenet N, Dreux M, Nisole S. Interplay Between SARS-CoV2 and the Type I Interferon Response. PloS Pathog (2020) 16(7):e1008737. doi: 10.1371/journal.ppat.1008737

42. Acharya D, Liu G, Gack MU. Dysregulation of Type I Interferon Responses in COVID-19. Nat Rev Immunol (2020) 20(7):397-8. doi: 10.1038/s41577020-0346-x

43. Blanco-Melo D, Nilsson-Payant BE, Liu WC, Uhl S, Hoagland D, Moller R, et al. Imbalanced Host Response to SARS-CoV-2 Drives Development of COVID-19. Cell (2020) 181(5):1036-45.e9. doi: 10.1016/j.cell.2020.04.026

44. Galani IE, Rovina N, Lampropoulou V, Triantafyllia V, Manioudaki M, Pavlos E, et al. Untuned Antiviral Immunity in COVID-19 Revealed by Temporal Type I/III Interferon Patterns and Flu Comparison. Nat Immunol (2021) 22(1):32-40. doi: 10.1038/s41590-020-00840-x

45. Taefehshokr N, Taefehshokr S, Hemmat N, Heit B. Covid-19: Perspectives on Innate Immune Evasion. Front Immunol (2020) 11:580641. doi: 10.3389/ fimmu.2020.580641

46. Zhang Y, Zhang J, Chen Y, Luo B, Yuan Y, Huang F, et al. The ORF8 Protein of SARS-CoV-2 Mediates Immune Evasion Through Potently Downregulating MHC-I. (2020). Available at: https://wwwbiorxivorg/content/101101/ 20200524111823v1.

47. Wilk AJ, Rustagi A, Zhao NQ, Roque J, Martinez-Colon GJ, McKechnie JL, et al. A Single-Cell Atlas of the Peripheral Immune Response in Patients With Severe COVID-19. Nat Med (2020) 26(7):1070-6. doi: 10.1038/ s41591-020-0944-y

48. Giamarellos-Bourboulis EJ, Netea MG, Rovina N, Akinosoglou K, Antoniadou A, Antonakos N, et al. Complex Immune Dysregulation in COVID-19 Patients With Severe Respiratory Failure. Cell Host Microbe (2020) 27(6):992-1000.e3. doi: 10.1016/j.chom.2020.04.009

49. Gordon DE, Jang GM, Bouhaddou M, Xu J, Obernier K, White KM, et al. A SARS-CoV-2 Protein Interaction Map Reveals Targets for Drug Repurposing. Nature (2020) 583(7816):459-68. doi: 10.1038/s41586-0202286-9

50. Lauro R, Irrera N, Eid AH, Bitto A. Could Antigen Presenting Cells Represent a Protective Element During SARS-CoV-2 Infection in Children? Pathogens (2021) 10(4):476. doi: 10.3390/pathogens10040476

51. Sette A, Crotty S. Adaptive Immunity to SARS-CoV-2 and COVID-19. Cell (2021) 184(4):861-80. doi: 10.1016/j.cell.2021.01.007

52. Shibabaw T, Molla MD, Teferi B, Ayelign B. Role of IFN and Complements System: Innate Immunity in SARS-CoV-2. J Inflamm Res (2020) 13:507-18. doi: $10.2147 /$ JIR.S267280

53. Poland GA, Ovsyannikova IG, Kennedy RB. SARS-CoV-2 Immunity: Review and Applications to Phase 3 Vaccine Candidates. Lancet (2020) 396(10262):1595-606. doi: 10.1016/S0140-6736(20)32137-1

54. Wack A. Monocyte and Dendritic Cell Defects in COVID-19. Nat Cell Biol (2021) 23(5):445-7. doi: 10.1038/s41556-021-00685-y

55. Sekine T, Perez-Potti A, Rivera-Ballesteros O, Stralin K, Gorin JB, Olsson A, et al. Robust $\mathrm{T}$ Cell Immunity in Convalescent Individuals With Asymptomatic or Mild COVID-19. Cell (2020) 183(1):158-68.e14. doi: 10.1016/j.cell.2020.08.017

56. Qin C, Zhou L, Hu Z, Zhang S, Yang S, Tao Y, et al. Dysregulation of Immune Response in Patients With Coronavirus 2019 (COVID-19) in Wuhan, China. Clin Infect Dis (2020) 71(15):762-8. doi: 10.1093/cid/ciaa248
57. Tay MZ, Poh CM, Renia L, MacAry PA, Ng LFP. The Trinity of COVID-19: Immunity, Inflammation and Intervention. Nat Rev Immunol (2020) 20 (6):363-74. doi: 10.1038/s41577-020-0311-8

58. Boppana S, Qin K, Files JK, Russell RM, Stoltz R, Bibollet-Ruche F, et al. SARS-CoV-2-Specific Circulating T Follicular Helper Cells Correlate With Neutralizing Antibodies and Increase During Early Convalescence. PloS Pathog (2021) 17(7):e1009761. doi: 10.1371/journal.ppat.1009761

59. Deenick EK, Ma CS. The Regulation and Role of T Follicular Helper Cells in Immunity. Immunology (2011) 134(4):361-7. doi: 10.1111/j.13652567.2011.03487.x

60. Ni L, Ye F, Cheng ML, Feng Y, Deng YQ, Zhao H, et al. Detection of SARSCoV-2-Specific Humoral and Cellular Immunity in COVID-19 Convalescent Individuals. Immunity (2020) 52(6):971-7.e3. doi: 10.1016/ j.immuni.2020.04.023

61. Sterlin D, Mathian A, Miyara M, Mohr A, Anna F, Claer L, et al. IgA Dominates the Early Neutralizing Antibody Response to SARS-CoV-2. Sci Trans Med (2021) 13(577):eabd2223. doi: 10.1126/scitranslmed.abd2223

62. Belogiannis K, Florou VA, Fragkou PC, Ferous S, Chatzis L, Polyzou A, et al. SARS-CoV-2 Antigenemia as a Confounding Factor in Immunodiagnostic Assays: A Case Study. Viruses (2021) 13(6):1143. doi: 10.3390/v13061143

63. Ibarrondo FJ, Fulcher JA, Goodman-Meza D, Elliott J, Hofmann C, Hausner MA, et al. Rapid Decay of Anti-SARS-CoV-2 Antibodies in Persons With Mild Covid-19. N Engl J Med (2020) 383(11):1085-7. doi: 10.1056/ NEJMc2025179

64. Roltgen K, Wirz OF, Stevens BA, Powell AE, Hogan CA, Najeeb J, et al. SARS-CoV-2 Antibody Responses Correlate With Resolution of RNAemia But Are Short-Lived in Patients With Mild Illness. (2020). Available at: https:// wwwmedrxivorg/content/101101/2020081520175794v1.

65. Martin-Vicente M, Almansa R, Martínez I, Tedim AP, Bustamante E, Tamayo L, et al. Absent or Insufficient Anti-SARS-CoV-2 S Antibodies at ICU Admission Are Associated to Higher Viral Loads in Plasma, Antigenemia and Mortality in COVID-19 Patients. (2021). Available at: https:// wwwmedrxivorg/content/101101/2021030821253121v1.

66. Zhang Q, Bastard P, Liu Z, Le Pen J, Moncada-Velez M, Chen J, et al. Inborn Errors of Type I IFN Immunity in Patients With Life-Threatening COVID19. Science (2020) 370(6515):eabd4570. doi: 10.1126/science.abd4570

67. Bastard P, Rosen LB, Zhang Q, Michailidis E, Hoffmann HH, Zhang Y, et al. Autoantibodies Against Type I IFNs in Patients with Life-Threatening COVID-19. Science (2020) 370(6515):eabd4585. doi: 10.1126/science. abd4585

68. Karaderi T, Bareke H, Kunter I, Seytanoglu A, Cagnan I, Balci D, et al. Host Genetics at the Intersection of Autoimmunity and COVID-19: A Potential Key for Heterogeneous COVID-19 Severity. Front Immunol (2020) 11:586111. doi: 10.3389/fimmu.2020.586111

69. Su Y, Chen D, Yuan D, Lausted C, Choi J, Dai CL, et al. Multi-Omics Resolves a Sharp Disease-State Shift Between Mild and Moderate COVID19. Cell (2020) 183(6):1479-95.e20. doi: 10.1016/j.cell.2020.10.037

70. Overmyer KA, Shishkova E, Miller IJ, Balnis J, Bernstein MN, Peters-Clarke TM, et al. Large-Scale Multi-Omic Analysis of COVID-19 Severity. Cell Syst (2021) 12(1):23-40.e7. doi: 10.1016/j.cels.2020.10.003

71. Schulte-Schrepping J, Reusch N, Paclik D, Bassler K, Schlickeiser S, Zhang B, et al. Severe COVID-19 Is Marked by a Dysregulated Myeloid Cell Compartment. Cell (2020) 182(6):1419-40.e23. doi: 10.1016/j.cell. 2020.08.001

72. Silvin A, Chapuis N, Dunsmore G, Goubet AG, Dubuisson A, Derosa L, et al. Elevated Calprotectin and Abnormal Myeloid Cell Subsets Discriminate Severe From Mild COVID-19. Cell (2020) 182(6):1401-18.e18. doi: 10.1016/ j.cell.2020.08.002

73. Chevrier S, Zurbuchen Y, Cervia C, Adamo S, Raeber ME, de Souza N, et al. A Distinct Innate Immune Signature Marks Progression From Mild to Severe COVID-19. Cell Rep Med (2021) 2(1):100166. doi: 10.1016/ j.xcrm.2020.100166

74. Daamen AR, Bachali P, Owen KA, Kingsmore KM, Hubbard EL, Labonte AC, et al. Comprehensive Transcriptomic Analysis of COVID-19 Blood, Lung, and Airway. Sci Rep (2021) 11(1):7052. doi: 10.1038/s41598-02186002-x

75. Kusnadi A, Ramirez-Suastegui C, Fajardo V, Chee SJ, Meckiff BJ, Simon H, et al. Severely Ill COVID-19 Patients Display Impaired Exhaustion Features 
in SARS-CoV-2-Reactive CD8(+) T Cells. Sci Immunol (2021) 6(55): eabe4782. doi: 10.1126/sciimmunol.abe4782

76. Ravichandran S, Lee Y, Grubbs G, Coyle EM, Klenow L, Akasaka O, et al. Longitudinal Antibody Repertoire in "Mild" Versus "Severe" COVID-19 Patients Reveals Immune Markers Associated With Disease Severity and Resolution. Sci $A d v$ (2021) 7(10):eabf2467. doi: 10.1126/sciadv.abf2467

77. Zohar T, Loos C, Fischinger S, Atyeo C, Wang C, Slein MD, et al. Compromised Humoral Functional Evolution Tracks With SARS-CoV-2 Mortality. Cell (2020) 183(6):1508-19.e12. doi: 10.1016/j.cell.2020.10.052

78. Gomez-Rial J, Rivero-Calle I, Salas A, Martinon-Torres F. Role of Monocytes/Macrophages in Covid-19 Pathogenesis: Implications for Therapy. Infect Drug Resist (2020) 13:2485-93. doi: 10.2147/IDR.S258639

79. Mehta P, McAuley DF, Brown M, Sanchez E, Tattersall RS, Manson JJ, et al. COVID-19: Consider Cytokine Storm Syndromes and Immunosuppression. Lancet (2020) 395(10229):1033-4. doi: 10.1016/S0140-6736(20)30628-0

80. Damsky W, Peterson D, King B. When Interferon Tiptoes Through COVID19: Pernio-Like Lesions and Their Prognostic Implications During SARSCoV-2 Infection. J Am Acad Dermatol (2020) 83(3):e269-70. doi: 10.1016/ j.jaad.2020.06.052

81. Wang N, Zhan Y, Zhu L, Hou Z, Liu F, Song P, et al. Retrospective Multicenter Cohort Study Shows Early Interferon Therapy Is Associated With Favorable Clinical Responses in COVID-19 Patients. Cell Host Microbe (2020) 28(3):455-64.e2. doi: 10.1016/j.chom.2020.07.005

82. Perico L, Benigni A, Casiraghi F, Ng LFP, Renia L, Remuzzi G. Immunity, Endothelial Injury and Complement-Induced Coagulopathy in COVID-19. Nat Rev Nephrol (2021) 17(1):46-64. doi: 10.1038/s41581-020-00357-4

83. Lucas C, Wong P, Klein J, Castro TBR, Silva J, Sundaram M, et al. Longitudinal Analyses Reveal Immunological Misfiring in Severe COVID19. Nature (2020) 584(7821):463-9. doi: 10.1038/s41586-020-2588-y

84. Sinha P, Matthay MA, Calfee CS. Is a "Cytokine Storm" Relevant to COVID19? JAMA Internal Med (2020) 180(9):1152-4. doi: 10.1001/jamaintern med.2020.3313

85. Peckham H, de Gruijter NM, Raine C, Radziszewska A, Ciurtin C, Wedderburn LR, et al. Male Sex Identified by Global COVID-19 MetaAnalysis as a Risk Factor for Death and ITU Admission. Nat Commun (2020) 11(1):6317. doi: 10.1038/s41467-020-19741-6

86. Bonafe M, Prattichizzo F, Giuliani A, Storci G, Sabbatinelli J, Olivieri F. Inflamm-Aging: Why Older Men Are the Most Susceptible to SARS-CoV-2 Complicated Outcomes. Cytokine Growth Factor Rev (2020) 53:33-7. doi: 10.1016/j.cytogfr.2020.04.005

87. Chiappelli F, Khakshooy A, Greenberg G. CoViD-19 Immunopathology and Immunotherapy. Bioinformation (2020) 16(3):219-22. doi: 10.6026/ 97320630016219

88. Franceschi C, Garagnani P, Vitale G, Capri M, Salvioli S. Inflammaging and 'Garb-Aging'. Trends Endocrinol Metab (2017) 28(3):199-212. doi: 10.1016/ j.tem.2016.09.005

89. Akbar AN, Gilroy DW. Aging Immunity May Exacerbate COVID-19. Science (2020) 369(6501):256-7. doi: 10.1126/science.abb0762

90. Pedersen SF, Ho YC. SARS-CoV-2: A Storm Is Raging. J Clin Invest (2020) 130(5):2202-5. doi: 10.1172/JCI137647

91. Shen B, Yi X, Sun Y, Bi X, Du J, Zhang C, et al. Proteomic and Metabolomic Characterization of COVID-19 Patient Sera. Cell (2020) 182(1):59-72.e15. doi: 10.1016/j.cell.2020.05.032

92. Liao M, Liu Y, Yuan J, Wen Y, Xu G, Zhao J, et al. Single-Cell Landscape of Bronchoalveolar Immune Cells in Patients With COVID-19. Nat Med (2020) 26(6):842-4. doi: 10.1038/s41591-020-0901-9

93. Hottz ED, Azevedo-Quintanilha IG, Palhinha L, Teixeira L, Barreto EA, Pao CRR, et al. Platelet Activation and Platelet-Monocyte Aggregate Formation Trigger Tissue Factor Expression in Patients With Severe COVID-19. Blood (2020) 136(11):1330-41. doi: 10.1182/blood.2020007252

94. Parackova Z, Zentsova I, Bloomfield M, Vrabcova P, Smetanova J, Klocperk A, et al. Disharmonic Inflammatory Signatures in COVID-19: Augmented Neutrophils' But Impaired Monocytes' and Dendritic Cells' Responsiveness. Cells (2020) 9(10):2206. doi: 10.3390/cells9102206

95. Song CY, Xu J, He JQ, Lu YQ. Immune Dysfunction Following COVID-19, Especially in Severe Patients. Sci Rep (2020) 10(1):15838. doi: 10.1038/ s41598-020-72718-9
96. Theoharides TC. COVID-19, Pulmonary Mast Cells, Cytokine Storms, and Beneficial Actions of Luteolin. BioFactors (2020) 46(3):306-8. doi: 10.1002/ biof. 1633

97. Channappanavar R, Perlman S. Pathogenic Human Coronavirus Infections: Causes and Consequences of Cytokine Storm and Immunopathology. Semin Immunopathol (2017) 39(5):529-39. doi: 10.1007/s00281-017-0629-x

98. Wu D, Yang XO. TH17 Responses in Cytokine Storm of COVID-19: An Emerging Target of JAK2 Inhibitor Fedratinib. J Microbiol Immunol Infect (2020) 53(3):368-70. doi: 10.1016/j.jmii.2020.03.005

99. Gorgoulis V, Adams PD, Alimonti A, Bennett DC, Bischof O, Bishop C, et al. Cellular Senescence: Defining a Path Forward. Cell (2019) 179(4):813-27. doi: 10.1016/j.cell.2019.10.005

100. Baz-Martinez M, Da Silva-Alvarez S, Rodriguez E, Guerra J, El Motiam A, Vidal A, et al. Cell Senescence Is an Antiviral Defense Mechanism. Sci Rep (2016) 6:37007. doi: 10.1038/srep37007

101. Munoz-Espin D, Serrano M. Cellular Senescence: From Physiology to Pathology. Nat Rev Mol Cell Biol (2014) 15(7):482-96. doi: 10.1038/nrm3823

102. Kelley WJ, Zemans RL, Goldstein DR. Cellular Senescence: Friend or Foe to Respiratory Viral Infections? Eur Respir J (2020) 56(6):2002708. doi: 10.1183/13993003.02708-2020

103. He S, Sharpless NE. Senescence in Health and Disease. Cell (2017) 169 (6):1000-11. doi: 10.1016/j.cell.2017.05.015

104. Ren Y, Shu T, Wu D, Mu J, Wang C, Huang M, et al. The ORF3a Protein of SARS-CoV-2 Induces Apoptosis in Cells. Cell Mol Immunol (2020) 17 (8):881-3. doi: 10.1038/s41423-020-0485-9

105. Yap JKY, Moriyama M, Iwasaki A. Inflammasomes and Pyroptosis as Therapeutic Targets for COVID-19. J Immunol (2020) 205(2):307-12. doi: 10.4049/jimmunol.2000513

106. Andersson U, Ottestad W, Tracey KJ. Extracellular HMGB1: A Therapeutic Target in Severe Pulmonary Inflammation Including COVID-19? Mol Med (2020) 26(1):42. doi: 10.1186/s10020-020-00172-4

107. Huanzhou Xu SAC, Ibukun A, Julia C, John A, Michael T. McIntosh, View ORCID ProfileSumita Bhaduri-McIntosh. SARS-CoV-2 Viroporin Triggers the NLRP3 Inflammatory Pathway. (2020). Available at: https:// wwwbiorxivorg/content/101101/20201027357731v1.

108. Wang Z, Zhang S, Xiao Y, Zhang W, Wu S, Qin T, et al. NLRP3 Inflammasome and Inflammatory Diseases. Oxid Med Cell Longevity (2020) 2020:4063562. doi: 10.1155/2020/4063562

109. Lara PC, Macias-Verde D, Burgos-Burgos J. Age-Induced NLRP3 Inflammasome Over-Activation Increases Lethality of SARS-CoV-2 Pneumonia in Elderly Patients. Aging Dis (2020) 11(4):756-62. doi: 10.14336/AD.2020.0601

110. Wang F, Hou H, Luo Y, Tang G, Wu S, Huang M, et al. The Laboratory Tests and Host Immunity of COVID-19 Patients With Different Severity of Illness. JCI Insight (2020) 5(10):e137799. doi: 10.1172/jci.insight.137799

111. Xiong Y, Liu Y, Cao L, Wang D, Guo M, Jiang A, et al. Transcriptomic Characteristics of Bronchoalveolar Lavage Fluid and Peripheral Blood Mononuclear Cells in COVID-19 Patients. Emerg Microbes Infect (2020) 9 (1):761-70. doi: 10.1080/22221751.2020.1747363

112. Ye Q, Wang B, Mao J. The Pathogenesis and Treatment of the 'Cytokine Storm' in COVID-19. J Infect (2020) 80(6):607-13. doi: 10.1016/ j.jinf.2020.03.037

113. Zmijewski JW, Pittet JF. Human Leukocyte Antigen-DR Deficiency and Immunosuppression-Related End-Organ Failure in SARS-CoV2 Infection. Anesth Analg (2020) 131(4):989-92. doi: 10.1213/ANE.0000000000005140

114. Zhou R, To KK, Wong YC, Liu L, Zhou B, Li X, et al. Acute SARS-CoV-2 Infection Impairs Dendritic Cell and T Cell Responses. Immunity (2020) 53 (4):864-77.e5. doi: 10.1172/jci.insight.137799

115. van Eeden C, Khan L, Osman MS, Cohen Tervaert JW. Natural Killer Cell Dysfunction and Its Role in COVID-19. Int J Mol Sci (2020) 21(17):6351. doi: $10.3390 /$ ijms 21176351

116. Wang F, Nie J, Wang H, Zhao Q, Xiong Y, Deng L, et al. Characteristics of Peripheral Lymphocyte Subset Alteration in COVID-19 Pneumonia. J Infect Dis (2020) 221(11):1762-9. doi: 10.1093/infdis/jiaa150

117. Zheng M, Gao Y, Wang G, Song G, Liu S, Sun D, et al. Functional Exhaustion of Antiviral Lymphocytes in COVID-19 Patients. Cell Mol Immunol (2020) 17(5):533-5. doi: 10.1038/s41423-020-0402-2 
118. Du Y, Tu L, Zhu P, Mu M, Wang R, Yang P, et al. Clinical Features of 85 Fatal Cases of COVID-19 From Wuhan. A Retrospective Observational Study. Am J Respir Crit Care Med (2020) 201(11):1372-9. doi: 10.1164/rccm.2020030543OC

119. Agrati C, Sacchi A, Bordoni V, Cimini E, Notari S, Grassi G, et al. Expansion of Myeloid-Derived Suppressor Cells in Patients With Severe Coronavirus Disease (COVID-19). Cell Death Differ (2020) 27(11):3196-207. doi: 10.1038/s41418-020-0572-6

120. Reyes M, Filbin MR, Bhattacharyya RP, Sonny A, Mehta A, Billman K, et al. Induction of a Regulatory Myeloid Program in Bacterial Sepsis and Severe COVID-19. bioRxiv (2020). doi: 10.1101/2020.09.02.280180

121. Rowlands M, Segal F, Hartl D. Myeloid-Derived Suppressor Cells as a Potential Biomarker and Therapeutic Target in COVID-19. Front Immunol (2021) 12:697405. doi: 10.3389/fimmu.2021.697405

122. Veglia F, Sanseviero E, Gabrilovich DI. Myeloid-Derived Suppressor Cells in the Era of Increasing Myeloid Cell Diversity. Nat Rev Immunol (2021) 21 (8):485-98. doi: 10.1038/s41577-020-00490-y

123. Tan L, Wang Q, Zhang D, Ding J, Huang Q, Tang YQ, et al. Lymphopenia Predicts Disease Severity of COVID-19: A Descriptive and Predictive Study. Signal Transduct Target Ther (2020) 5(1):33. doi: 10.1038/s41392-0200148-4

124. Li J, Guo M, Tian X, Wang X, Yang X, Wu P, et al. Virus-Host Interactome and Proteomic Survey Reveal Potential Virulence Factors Influencing SARS-CoV-2 Pathogenesis. Med (2021) 2(1):99-112.e7. doi: 10.1016/ j.medj.2020.07.002

125. Diao B, Wang C, Tan Y, Chen X, Liu Y, Ning L, et al. Reduction and Functional Exhaustion of T Cells in Patients With Coronavirus Disease 2019 (COVID-19). Front Immunol (2020) 11:827. doi: 10.3389/fimmu.2020.00827

126. De Biasi S, Meschiari M, Gibellini L, Bellinazzi C, Borella R, Fidanza L, et al. Marked T Cell Activation, Senescence, Exhaustion and Skewing Towards TH17 in Patients With COVID-19 Pneumonia. Nat Commun (2020) 11 (1):3434. doi: 10.21203/rs.3.rs-23957/v1

127. Asrani P, Hassan MI. SARS-CoV-2 Mediated Lung Inflammatory Responses in Host: Targeting the Cytokine Storm for Therapeutic Interventions. Mol Cell Biochem (2021) 476(2):675-87. doi: 10.1007/s11010-020-03935-Z

128. Hotchkiss RS, Monneret G, Payen D. Sepsis-Induced Immunosuppression: From Cellular Dysfunctions to Immunotherapy. Nat Rev Immunol (2013) 13 (12):862-74. doi: 10.1038/nri3552

129. Galvan-Pena S, Leon J, Chowdhary K, Michelson DA, Vijaykumar B, Yang L, et al. Profound Treg Perturbations Correlate With COVID-19 Severity. bioRxiv: Preprint Server Biol (2020). doi: 10.1101/2020.12.11.416180

130. Kuri-Cervantes L, Pampena MB, Meng W, Rosenfeld AM, Ittner CAG, Weisman AR, et al. Comprehensive Mapping of Immune Perturbations Associated With Severe COVID-19. Sci Immunol (2020) 5(49):eabd7114. doi: 10.1126/sciimmunol.abd7114

131. Seydoux E, Homad LJ, MacCamy AJ, Parks KR, Hurlburt NK, Jennewein $\mathrm{MF}$, et al. Analysis of a SARS-CoV-2-Infected Individual Reveals Development of Potent Neutralizing Antibodies With Limited Somatic Mutation. Immunity (2020) 53(1):98-105.e5. doi: 10.1016/j.immuni. 2020.06 .001

132. Juno JA, Tan HX, Lee WS, Reynaldi A, Kelly HG, Wragg K, et al. Humoral and Circulating Follicular Helper T Cell Responses in Recovered Patients With COVID-19. Nat Med (2020) 26(9):1428-34. doi: 10.1038/s41591-0200995-0

133. Atyeo C, Fischinger S, Zohar T, Slein MD, Burke J, Loos C, et al. Distinct Early Serological Signatures Track With SARS-CoV-2 Survival. Immunity (2020) 53(3):524-32.e4. doi: 10.1016/j.immuni.2020.07.020

134. Chakraborty S, Gonzalez J, Edwards K, Mallajosyula V, Buzzanco AS, Sherwood R, et al. Proinflammatory IgG Fc Structures in Patients With Severe COVID-19. Nat Immunol (2021) 22(1):67-73. doi: 10.1038/s41590020-00828-7

135. Liu L, Wei Q, Lin Q, Fang J, Wang H, Kwok H, et al. Anti-Spike IgG Causes Severe Acute Lung Injury by Skewing Macrophage Responses During Acute SARS-CoV Infection. JCI Insight (2019) 4(4):e123158. doi: 10.1172/ jci.insight. 123158

136. Levi M, van der Poll T, Buller HR. Bidirectional Relation Between Inflammation and Coagulation. Circulation (2004) 109(22):2698-704. doi: 10.1161/01.CIR.0000131660.51520.9A
137. Jin Y, Ji W, Yang H, Chen S, Zhang W, Duan G. Endothelial Activation and Dysfunction in COVID-19: From Basic Mechanisms to Potential Therapeutic Approaches. Signal Transduct Target Ther (2020) 5(1):293. doi: 10.1038/s41392-020-00454-7

138. Varga Z, Flammer AJ, Steiger P, Haberecker M, Andermatt R, Zinkernagel AS, et al. Endothelial Cell Infection and Endotheliitis in COVID-19. Lancet (2020) 395(10234):1417-8. doi: 10.1016/S0140-6736(20)30937-5

139. Buzhdygan TP, DeOre BJ, Baldwin-Leclair A, Bullock TA, McGary HM, Khan JA, et al. The SARS-CoV-2 Spike Protein Alters Barrier Function in 2D Static and 3D Microfluidic In-Vitro Models of the Human Blood-Brain Barrier. Neurobiol Dis (2020) 146:105131. doi: 10.1016/j.nbd.2020.105131

140. Ackermann M, Verleden SE, Kuehnel M, Haverich A, Welte T, Laenger F, et al. Pulmonary Vascular Endothelialitis, Thrombosis, and Angiogenesis in Covid-19. N Engl J Med (2020) 383(2):120-8. doi: 10.1056/NEJMoa2015432

141. Kempuraj D, Selvakumar GP, Ahmed ME, Raikwar SP, Thangavel R, Khan A, et al. COVID-19, Mast Cells, Cytokine Storm, Psychological Stress, and Neuroinflammation. Neurosci (2020) 26(5-6):402-14. doi: 10.1177/ 1073858420941476

142. Alexopoulos H, Magira E, Bitzogli K, Kafasi N, Vlachoyiannopoulos P, Tzioufas A, et al. Anti-SARS-CoV-2 Antibodies in the CSF, Blood-Brain Barrier Dysfunction, and Neurological Outcome: Studies in 8 Stuporous and Comatose Patients. Neurol(R) Neuroimmunol Neuroinflamm (2020) 7(6): e893. doi: 10.1212/NXI.0000000000000893

143. Libby P, Luscher T. COVID-19 Is, in the End, an Endothelial Disease. Eur Heart J (2020) 41(32):3038-44. doi: 10.1093/eurheartj/ehaa623

144. Bryce C, Grimes Z, Pujadas E, Ahuja S, Beasley MB, Albrecht R, et al. Pathophysiology of SARS-CoV-2: The Mount Sinai COVID-19 Autopsy Experience. Mod Pathol (2021) 34(8):1456-67. doi: 10.1038/s41379-02100793-y

145. Maiese A, Manetti AC, La Russa R, Di Paolo M, Turillazzi E, Frati P, et al. Autopsy Findings in COVID-19-Related Deaths: A Literature Review. Forensic Sci Med Pathol (2020) 17:279-96. doi: 10.1007/s12024-020-00310-8

146. Gupta A, Madhavan MV, Sehgal K, Nair N, Mahajan S, Sehrawat TS, et al. Extrapulmonary Manifestations of COVID-19. Nat Med (2020) 26(7):101732. doi: 10.1038/s41591-020-0968-3

147. Engelmann B, Massberg S. Thrombosis as an Intravascular Effector of Innate Immunity. Nat Rev Immunol (2013) 13(1):34-45. doi: 10.1038/nri3345

148. Malas MB, Naazie IN, Elsayed N, Mathlouthi A, Marmor R, Clary B. Thromboembolism Risk of COVID-19 is High and Associated With a Higher Risk of Mortality: A Systematic Review and Meta-Analysis. EClinicalMedicine (2020) 29:100639. doi: 10.1016/j.eclinm.2020.100639

149. Bonaventura A, Vecchie A, Dagna L, Martinod K, Dixon DL, Van Tassell BW, et al. Endothelial Dysfunction and Immunothrombosis as Key Pathogenic Mechanisms in COVID-19. Nat Rev Immunol (2021) 21 (5):319-29. doi: 10.1038/s41577-021-00536-9

150. Shaw RJ, Bradbury C, Abrams ST, Wang G, Toh CH. COVID-19 and Immunothrombosis: Emerging Understanding and Clinical Management. $\mathrm{Br}$ J Haematol (2021) 194(3):518-29. doi: 10.1111/bjh.17664

151. Bernardes JP, Mishra N, Tran F, Bahmer T, Best L, Blase JI, et al. Longitudinal Multi-Omics Analyses Identify Responses of Megakaryocytes, Erythroid Cells, and Plasmablasts as Hallmarks of Severe COVID-19. Immunity (2020) 53(6):1296-314.e9. doi: 10.1016/j.immuni.2020.11.017

152. Roncati L, Ligabue G, Nasillo V, Lusenti B, Gennari W, Fabbiani L, et al. A Proof of Evidence Supporting Abnormal Immunothrombosis in Severe COVID-19: Naked Megakaryocyte Nuclei Increase in the Bone Marrow and Lungs of Critically Ill Patients. Platelets (2020) 31(8):1085-9. doi: 10.1080/09537104.2020.1810224

153. Thachil J, Lisman T. Pulmonary Megakaryocytes in Coronavirus Disease 2019 (COVID-19): Roles in Thrombi and Fibrosis. Semin Thromb Hemost (2020) 46(7):831-4. doi: 10.1055/s-0040-1714274

154. Manne BK, Denorme F, Middleton EA, Portier I, Rowley JW, Stubben C, et al. Platelet Gene Expression and Function in Patients With COVID-19. Blood (2020) 136(11):1317-29. doi: 10.1182/blood.2020007214

155. Zaid Y, Puhm F, Allaeys I, Naya A, Oudghiri M, Khalki L, et al. Platelets Can Associate With SARS-Cov-2 RNA and Are Hyperactivated in COVID-19. Circ Res (2020) 127:1404-18. doi: 10.1161/CIRCRESAHA.120.317703

156. Taus F, Salvagno G, Cane S, Fava C, Mazzaferri F, Carrara E, et al. Platelets Promote Thromboinflammation in SARS-CoV-2 Pneumonia. Arterioscler 
Thromb Vasc Biol (2020) 40(12):2975-89. doi: 10.1161/ATVBAHA. 120.315175

157. Radermecker C, Detrembleur N, Guiot J, Cavalier E, Henket M, d'Emal C, et al. Neutrophil Extracellular Traps Infiltrate the Lung Airway, Interstitial, and Vascular Compartments in Severe COVID-19. J Exp Med (2020) 217 (12):e20201012. doi: 10.1084/jem.20201012

158. Zuo Y, Yalavarthi S, Shi H, Gockman K, Zuo M, Madison JA, et al. Neutrophil Extracellular Traps in COVID-19. JCI Insight (2020) 5(11): e138999. doi: 10.1172/jci.insight.138999

159. Leppkes M, Knopf J, Naschberger E, Lindemann A, Singh J, Herrmann I, et al. Vascular Occlusion by Neutrophil Extracellular Traps in COVID-19. EBioMedicine (2020) 58:102925. doi: 10.1016/j.ebiom.2020.102925

160. Veras FP, Pontelli MC, Silva CM, Toller-Kawahisa JE, de Lima M, Nascimento DC, et al. SARS-CoV-2-Triggered Neutrophil Extracellular Traps Mediate COVID-19 Pathology. J Exp Med (2020) 217(12): e20201129. doi: 10.1084/jem.20201129

161. Ackermann M, Anders HJ, Bilyy R, Bowlin GL, Daniel C, De Lorenzo R, et al. Patients With COVID-19: In the Dark-NETs of Neutrophils. Cell Death Differ (2021) 28:1-15. doi: 10.1038/s41418-021-00805-z

162. Englert H, Rangaswamy C, Deppermann C, Sperhake JP, Krisp C, Schreier D, et al. Defective NET Clearance Contributes to Sustained FXII Activation in COVID-19-Associated Pulmonary Thrombo-Inflammation. EBioMedicine (2021) 67:103382. doi: 10.1016/j.ebiom.2021.103382

163. Skendros P, Mitsios A, Chrysanthopoulou A, Mastellos DC, Metallidis S, Rafailidis $\mathrm{P}$, et al. Complement and Tissue Factor-Enriched Neutrophil Extracellular Traps Are Key Drivers in COVID-19 Immunothrombosis. J Clin Invest (2020) 130(11):6151-7. doi: 10.1172/JCI141374

164. Lo MW, Kemper C, Woodruff TM. COVID-19: Complement, Coagulation, and Collateral Damage. J Immunol (2020) 205(6):1488-95. doi: 10.4049/ jimmunol.2000644

165. Magro C, Mulvey JJ, Berlin D, Nuovo G, Salvatore S, Harp J, et al. Complement Associated Microvascular Injury and Thrombosis in the Pathogenesis of Severe COVID-19 Infection: A Report of Five Cases. Trans Res (2020) 220:1-13. doi: 10.1016/j.trsl.2020.04.007

166. Cugno M, Meroni PL, Gualtierotti R, Griffini S, Grovetti E, Torri A, et al. Complement Activation and Endothelial Perturbation Parallel COVID-19 Severity and Activity. J Autoimmun (2021) 116:102560. doi: 10.1016/ j.jaut.2020.102560

167. Mastellos DC, Pires da Silva BGP, Fonseca BAL, Fonseca NP, AuxiliadoraMartins M, Mastaglio S, et al. Complement C3 vs C5 Inhibition in Severe COVID-19: Early Clinical Findings Reveal Differential Biological Efficacy. Clin Immunol (2020) 220:108598. doi: 10.1016/j.clim.2020.108598

168. Zinellu A, Mangoni AA. Serum Complement C3 and C4 and COVID-19 Severity and Mortality: A Systematic Review and Meta-Analysis With MetaRegression. Front Immunol (2021) 12:696085. doi: 10.3389/ fimmu.2021.696085

169. Busch MH, Timmermans S, Nagy M, Visser M, Huckriede J, Aendekerk JP, et al. Neutrophils and Contact Activation of Coagulation as Potential Drivers of COVID-19. Circulation (2020) 142(18):1787-90. doi: 10.1161/ CIRCULATIONAHA. 120.050656

170. Du F, Liu B, Zhang S. COVID-19: The Role of Excessive Cytokine Release and Potential ACE2 Down-Regulation in Promoting Hypercoagulable State Associated With Severe Illness. J Thromb Thrombol (2020) 51:313-29. doi: 10.1007/s11239-020-02224-2

171. Zuo Y, Estes SK, Ali RA, Gandhi AA, Yalavarthi S, Shi H, et al. Prothrombotic Autoantibodies in Serum From Patients Hospitalized With COVID-19. Sci Trans Med (2020) 12(570):eabd3876. doi: 10.1126/ scitranslmed.abd3876

172. Gando S, Wada T. Thromboplasminflammation in COVID-19 Coagulopathy: Three Viewpoints for Diagnostic and Therapeutic Strategies. Front Immunol (2021) 12:649122. doi: 10.3389/fimmu.2021.649122

173. Lipcsey M, Persson B, Eriksson O, Blom AM, Fromell K, Hultstrom M, et al. The Outcome of Critically Ill COVID-19 Patients Is Linked to Thromboinflammation Dominated by the Kallikrein/Kinin System. Front Immunol (2021) 12:627579. doi: 10.3389/fimmu.2021.627579

174. Stakos D, Skendros P, Konstantinides S, Ritis K. Traps N' Clots: NETMediated Thrombosis and Related Diseases. Thromb Haemost (2020) 120 (3):373-83. doi: 10.1055/s-0039-3402731
175. Zucoloto AZ, Jenne CN. Platelet-Neutrophil Interplay: Insights Into Neutrophil Extracellular Trap (NET)-Driven Coagulation in Infection. Front Cardiovasc Med (2019) 6:85. doi: 10.3389/fcvm.2019.00085

176. Middleton EA, He XY, Denorme F, Campbell RA, Ng D, Salvatore SP, et al. Neutrophil Extracellular Traps Contribute to Immunothrombosis in COVID-19 Acute Respiratory Distress Syndrome. Blood (2020) 136 (10):1169-79. doi: 10.1182/blood.2020007008

177. Icenogle T. COVID-19: Infection or Autoimmunity. Front Immunol (2020) 11:2055. doi: 10.3389/fimmu.2020.02055

178. Khoruts A, Fraser JM. A Causal Link Between Lymphopenia and Autoimmunity. Immunol Lett (2005) 98(1):23-31. doi: 10.1016/j. imlet.2004.10.022

179. Smatti MK, Cyprian FS, Nasrallah GK, Al Thani AA, Almishal RO, Yassine HM. Viruses and Autoimmunity: A Review on the Potential Interaction and Molecular Mechanisms. Viruses (2019) 11(8):762. doi: 10.3390/v11080762

180. Tang KT, Hsu BC, Chen DY. Autoimmune and Rheumatic Manifestations Associated With COVID-19 in Adults: An Updated Systematic Review. Front Immunol (2021) 12:645013. doi: 10.3389/fimmu.2021.645013

181. Knochelmann HM, Dwyer CJ, Bailey SR, Amaya SM, Elston DM, MazzaMcCrann JM, et al. When Worlds Collide: Th17 and Treg Cells in Cancer and Autoimmunity. Cell Mol Immunol (2018) 15(5):458-69. doi: 10.1038/ s41423-018-0004-4

182. Liblau RS, Wong FS, Mars LT, Santamaria P. Autoreactive CD8 T Cells in Organ-Specific Autoimmunity: Emerging Targets for Therapeutic Intervention. Immunity (2002) 17(1):1-6. doi: 10.1016/s1074-7613(02) 00338-2

183. Woodruff MC, Ramonell RP, Nguyen DC, Cashman KS, Saini AS, Haddad NS, et al. Extrafollicular B Cell Responses Correlate With Neutralizing Antibodies and Morbidity in COVID-19. Nat Immunol (2020) 21 (12):1506-16. doi: 10.1038/s41590-020-00814-Z

184. Yu HQ, Sun BQ, Fang ZF, Zhao JC, Liu XY, Li YM, et al. Distinct Features of SARS-CoV-2-Specific IgA Response in COVID-19 Patients. Eur Respir J (2020) 56(2):2001526. doi: 10.1183/13993003.01526-2020

185. Canas CA. The Triggering of Post-COVID-19 Autoimmunity Phenomena Could be Associated With Both Transient Immunosuppression and an Inappropriate Form of Immune Reconstitution in Susceptible Individuals. Med Hypotheses (2020) 145:110345. doi: 10.1016/j.mehy.2020.110345

186. Dotan A, Muller S, Kanduc D, David P, Halpert G, Shoenfeld Y. The SARS$\mathrm{CoV}-2$ as an Instrumental Trigger of Autoimmunity. Autoimmun Rev (2021) 20(4):102792. doi: 10.1016/j.autrev.2021.102792

187. Kanduc D. From Anti-SARS-CoV-2 Immune Responses to COVID-19 via Molecular Mimicry. Antibodies (2020) 9(3):33. doi: 10.3390/antib9030033

188. Kanduc D, Shoenfeld Y. Molecular Mimicry Between SARS-CoV-2 Spike Glycoprotein and Mammalian Proteomes: Implications for the Vaccine. Immunol Res (2020) 68(5):310-3. doi: 10.1007/s12026-020-09152-6

189. Rodriguez Y, Novelli L, Rojas M, De Santis M, Acosta-Ampudia Y, Monsalve DM, et al. Autoinflammatory and Autoimmune Conditions at the Crossroad of COVID-19. J Autoimmun (2020) 114:102506. doi: 10.1016/j.jaut.2020.102506

190. Apel F, Zychlinsky A, Kenny EF. The Role of Neutrophil Extracellular Traps in Rheumatic Diseases. Nat Rev Rheumatol (2018) 14(8):467-75. doi: 10.1038/s41584-018-0039-z

191. Saheb Sharif-Askari N, Saheb Sharif-Askari F, Ahmed SBM, Hannawi S, Hamoudi R, Hamid Q, et al. Enhanced Expression of Autoantigens During SARS-CoV-2 Viral Infection. Front Immunol (2021) 12:686462. doi: 10.3389/fimmu.2021.686462

192. Vlachoyiannopoulos PG, Magira E, Alexopoulos H, Jahaj E, Theophilopoulou $\mathrm{K}$, Kotanidou A, et al. Autoantibodies Related to Systemic Autoimmune Rheumatic Diseases in Severely Ill Patients With COVID-19. Ann Rheum Dis (2020) 79(12):1661-3. doi: 10.1136/annrheumdis-2020-218009

193. Woodruff MC, Ramonell RP, Lee FE, Sanz I. Clinically Identifiable Autoreactivity Is Common in Severe SARS-CoV-2 Infection. (2020). Available at: https://wwwmedrxivorg/content/101101/2020102120216192v2.

194. Angileri F, Legare S, Marino Gammazza A, Conway de Macario E, Macario AJL, Cappello F. Is Molecular Mimicry the Culprit in the Autoimmune Haemolytic Anaemia Affecting Patients With COVID-19? Br J Haematol (2020) 190(2):e92-3. doi: 10.1111/bjh.16883 
195. Otani M, Kuroki A, Kikuchi S, Kihara M, Nakata J, Ito K, et al. Sialylation Determines the Nephritogenicity of IgG3 Cryoglobulins. J Am Soc Nephrol (2012) 23(11):1869-78. doi: 10.1681/ASN.2012050477

196. Greinacher A, Thiele T, Warkentin TE, Weisser K, Kyrle PA, Eichinger S. Thrombotic Thrombocytopenia After ChAdOx1 Ncov-19 Vaccination. $N$ Engl J Med (2021) 384(22):2092-101. doi: 10.1056/NEJMoa2104840

197. Ehrenfeld M, Tincani A, Andreoli L, Cattalini M, Greenbaum A, Kanduc D, et al. Covid-19 and Autoimmunity. Autoimmun Rev (2020) 19(8):102597. doi: 10.1016/j.autrev.2020.102597

198. Zacharias H, Dubey S, Koduri G, D'Cruz D. Rheumatological Complications of Covid 19. Autoimmun Rev (2021) 20(9):102883. doi: 10.1016/ j.autrev.2021.102883

199. Consiglio CR, Cotugno N, Sardh F, Pou C, Amodio D, Rodriguez L, et al. The Immunology of Multisystem Inflammatory Syndrome in Children With COVID-19. Cell (2020) 183(4):968-81.e7. doi: 10.1016/j.cell.2020.09.016

200. El Aoud S, Morin C, Lorriaux P, Obert J, Sorial D, Chaabouni T, et al. COVID-19 Presenting as Lupus Erythematosus-Like Syndrome. Disaster Med Public Health Prep (2020) 2020:1-4. doi: 10.1017/dmp.2020.358

201. Gracia-Ramos AE, Saavedra-Salinas MA. Can the SARS-CoV-2 Infection Trigger Systemic Lupus Erythematosus? A Case-Based Review. Rheumatol Int (2021) 41(4):799-809. doi: 10.1007/s00296-021-04794-7

202. Hali F, Jabri H, Chiheb S, Hafiani Y, Nsiri A. A Concomitant Diagnosis of COVID-19 Infection and Systemic Lupus Erythematosus Complicated by a Macrophage Activation Syndrome: A New Case Report. Int J Dermatol (2021) 60(8):1030-1. doi: 10.1111/ijd.15592

203. Mantovani Cardoso E, Hundal J, Feterman D, Magaldi J. Concomitant New Diagnosis of Systemic Lupus Erythematosus and COVID-19 With Possible Antiphospholipid Syndrome. Just a Coincidence? A Case Report and Review of Intertwining Pathophysiology. Clin Rheumatol (2020) 39(9):2811-5. doi: 10.1007/s10067-020-05310-1

204. Slimani Y, Abbassi R, El Fatoiki FZ, Barrou L, Chiheb S. Systemic Lupus Erythematosus and Varicella-Like Rash Following COVID-19 in a Previously Healthy Patient. J Med Virol (2021) 93(2):1184-7. doi: 10.1002/ jmv.26513

205. Perricone C, Shoenfeld N, Agmon-Levin N, de Carolis C, Perricone R, Shoenfeld Y. Smell and Autoimmunity: A Comprehensive Review. Clin Rev Allergy Immunol (2013) 45(1):87-96. doi: 10.1007/s12016-012-8343-x

206. Gagiannis D, Steinestel J, Hackenbroch C, Hannemann M, Umathum V, Gebauer N, et al. COVID-19-Induced Acute Respiratory Failure - An Exacerbation of Organ-Specific Autoimmunity? medRxiv (2020). doi: 10.1101/2020.04.27.20077180

207. Winchester N, Calabrese C, Calabrese LH. The Intersection of COVID-19 and Autoimmunity: What Is Our Current Understanding? Pathog Immun (2021) 6(1):31-54. doi: 10.20411/pai.v6i1.417

208. Spihlman AP, Gadi N, Wu SC, Moulton VR. COVID-19 and Systemic Lupus Erythematosus: Focus on Immune Response and Therapeutics. Front Immunol (2020) 11:589474. doi: 10.3389/fimmu.2020.589474

209. Emmi G, Bettiol A, Mattioli I, Silvestri E, Di Scala G, Urban ML, et al. SARSCoV-2 Infection Among Patients With Systemic Autoimmune Diseases. Autoimmun Rev (2020) 19(7):102575. doi: 10.1016/j.autrev.2020.102575

210. Rigamonti C, Cittone MG, De Benedittis C, Rizzi E, Casciaro GF, Bellan M, et al. Rates of Symptomatic SARS-CoV-2 Infection in Patients With Autoimmune Liver Diseases in Northern Italy: A Telemedicine Study. Clin Gastroenterol Hepatol (2020) 18(10):2369-71.e1. doi: 10.1016/j.cgh.2020.05.047

211. Duret PM, Sebbag E, Mallick A, Gravier S, Spielmann L, Messer L. Recovery From COVID-19 in a Patient With Spondyloarthritis Treated With TNFAlpha Inhibitor Etanercept. Ann Rheum Dis (2020) 79(9):1251-2. doi: 10.1136/annrheumdis-2020-217362

212. Mihai C, Dobrota R, Schroder M, Garaiman A, Jordan S, Becker MO, et al. COVID-19 in a Patient With Systemic Sclerosis Treated With Tocilizumab for SSc-ILD. Ann Rheum Dis (2020) 79(5):668-9. doi: 10.1136/annrheumdis2020-217442

213. Moutsopoulos HM. Anti-Inflammatory Therapy May Ameliorate the Clinical Picture of COVID-19. Ann Rheum Dis (2020) 79(9):1253-4. doi: 10.1136/annrheumdis-2020-217562

214. D'Silva KM, Wallace ZS. COVID-19 and Disease-Modifying AntiRheumatic Drugs. Curr Rheumatol Rep (2021) 23(5):28. doi: 10.1007/ s11926-021-00998-9
215. Sharmeen S, Elghawy A, Zarlasht F, Yao Q. COVID-19 in Rheumatic Disease Patients on Immunosuppressive Agents. Semin Arthritis Rheum (2020) 50 (4):680-6. doi: 10.1016/j.semarthrit.2020.05.010

216. Brenner EJ, Ungaro RC, Gearry RB, Kaplan GG, Kissous-Hunt M, Lewis JD, et al. Corticosteroids, But Not TNF Antagonists, Are Associated With Adverse COVID-19 Outcomes in Patients With Inflammatory Bowel Diseases: Results From an International Registry. Gastroenterology (2020) 159(2):481-91.e3. doi: 10.1053/j.gastro.2020.05.032

217. Akiyama S, Hamdeh S, Micic D, Sakuraba A. Prevalence and Clinical Outcomes of COVID-19 in Patients With Autoimmune Diseases: A Systematic Review and Meta-Analysis. Ann Rheum Dis (2020). doi: 10.1136/annrheumdis-2020-218946

218. Robinson PC, Morand E. Divergent Effects of Acute Versus Chronic Glucocorticoids in COVID-19. Lancet Rheumatol (2021) 3(3):e168-e70. doi: 10.1016/S2665-9913(21)00005-9

219. Schurink B, Roos E, Radonic T, Barbe E, Bouman CSC, de Boer HH, et al. Viral Presence and Immunopathology in Patients With Lethal COVID-19: A Prospective Autopsy Cohort Study. Lancet Microbe (2020) 1(7):e290-9. doi: 10.1016/S2666-5247(20)30144-0

220. Khamsi R. Rogue Antibodies Could be Driving Severe COVID-19. Nature (2021) 590(7844):29-31. doi: 10.1038/d41586-021-00149-1

221. Zuniga M, Gomes C, Carsons SE, Bender MT, Cotzia P, Miao QR, et al. Autoimmunity to Annexin A2 Predicts Mortality Among Hospitalised COVID-19 Patients. Eur Respir J (2021) 2100918. doi: 10.1183/ 13993003.00918-2021

222. Calabrese L, Winthrop KL. Rheumatology and COVID-19 at 1 Year: Facing the Unknowns. Ann Rheum Dis (2021) 80:679-81. doi: 10.1136/ annrheumdis-2021-219957

223. Proal AD, VanElzakker MB. Long COVID or Post-Acute Sequelae of COVID-19 (PASC): An Overview of Biological Factors That May Contribute to Persistent Symptoms. Front Microbiol (2021) 12:698169. doi: 10.3389/fmicb.2021.698169

224. Ramakrishnan RK, Kashour T, Hamid Q, Halwani R, Tleyjeh IM. Unraveling the Mystery Surrounding Post-Acute Sequelae of COVID-19. Front Immunol (2021) 12:686029. doi: 10.3389/fimmu.2021.686029

225. Alunno A, Najm A, Mariette X, De Marco G, Emmel J, Mason L, et al. Immunomodulatory Therapies for SARS-CoV-2 Infection: A Systematic Literature Review to Inform EULAR Points to Consider. Ann Rheum Dis (2021) 80:803-15. doi: 10.1136/annrheumdis-2020-219725

226. Investigators R-C, Gordon AC, Mouncey PR, Al-Beidh F, Rowan KM, Nichol $\mathrm{AD}$, et al. Interleukin-6 Receptor Antagonists in Critically Ill Patients With Covid-19. N Engl J Med (2021) 384:1491-502. doi: 10.1056/NEJMoa2100433

227. Kalil AC, Patterson TF, Mehta AK, Tomashek KM, Wolfe CR, Ghazaryan V, et al. Baricitinib Plus Remdesivir for Hospitalized Adults With Covid-19. N Engl J Med (2021) 384(9):795-807. doi: 10.1056/NEJMoa2031994

228. RECOVERY Collaborative Group, Horby PW, Pessoa-Amorim G, Peto L, Brightling CE, Sarkar R, et al. Tocilizumab in Patients Admitted to Hospital With COVID-19 (RECOVERY): Preliminary Results of a Randomised, Controlled, Open-Label, Platform Trial. (2021). Available at: https:// wwwmedrxivorg/content/101101/2021021121249258v1.

229. Rodriguez-Garcia JL, Sanchez-Nievas G, Arevalo-Serrano J, Garcia-Gomez C, Jimenez-Vizuete JM, Martinez-Alfaro E. Baricitinib Improves Respiratory Function in Patients Treated With Corticosteroids for SARS-CoV-2 Pneumonia: An Observational Cohort Study. Rheumatology (2021) 60 (1):399-407. doi: 10.1093/rheumatology/keaa587

230. Ray D, Yung R. Immune Senescence, Epigenetics and Autoimmunity. Clin Immunol (2018) 196:59-63. doi: 10.1016/j.clim.2018.04.002

231. Watad A, Bragazzi NL, Adawi M, Amital H, Toubi E, Porat BS, et al. Autoimmunity in the Elderly: Insights From Basic Science and Clinics - A Mini-Review. Gerontology (2017) 63(6):515-23. doi: 10.1159/000478012

232. Peng X, Ouyang J, Isnard S, Lin J, Fombuena B, Zhu B, et al. Sharing CD4+ T Cell Loss: When COVID-19 and HIV Collide on Immune System. Front Immunol (2020) 11:596631. doi: 10.3389/fimmu.2020.596631

233. Zaboli E, Majidi H, Alizadeh-Navaei R, Hedayatizadeh-Omran A, AsgarianOmran H, Vahedi Larijani L, et al. Lymphopenia and Lung Complications in Patients With Coronavirus Disease-2019 (COVID-19): A Retrospective Study Based on Clinical Data. J Med Virol (2021) 93(9):5425-31. doi: 10.1002/jmv.27060 
234. Ren X, Wen W, Fan X, Hou W, Su B, Cai P, et al. COVID-19 Immune Features Revealed by a Large-Scale Single-Cell Transcriptome Atlas. Cell (2021) 184(7):1895-913.e19. doi: 10.1016/j.cell.2021.01.053

235. Garcia GJr., Sharma A, Ramaiah A, Sen C, Purkayastha A, Kohn DB, et al. Antiviral Drug Screen Identifies DNA-Damage Response Inhibitor as Potent Blocker of SARS-CoV-2 Replication. Cell Rep (2021) 35(1):108940. doi: 10.1016/j.celrep.2021.108940

236. Dittmar M, Lee JS, Whig K, Segrist E, Li M, Kamalia B, et al. Drug Repurposing Screens Reveal Cell-Type-Specific Entry Pathways and FDAApproved Drugs Active Against SARS-Cov-2. Cell Rep (2021) 35(1):108959. doi: 10.1016/j.celrep.2021.108959

237. Camell CD, Yousefzadeh MJ, Zhu Y, Langhi Prata LGP, Huggins MA, Pierson M, et al. Senolytics Reduce Coronavirus-Related Mortality in Old Mice. Science (2021) 373(6552):eabe4832. doi: 10.1126/science.abe4832

238. Nehme J, Borghesan M, Mackedenski S, Bird TG, Demaria M. Cellular Senescence as a Potential Mediator of COVID-19 Severity in the Elderly. Aging Cell (2020) 19(10):e13237. doi: 10.1111/acel.13237

239. Myrianthopoulos V, Evangelou K, Vasileiou PVS, Cooks T, Vassilakopoulos TP, Pangalis GA, et al. Senescence and Senotherapeutics: A New Field in Cancer Therapy. Pharmacol Ther (2019) 193:31-49. doi: 10.1016/ j.pharmthera.2018.08.006

240. Cox LS, Lord JM. Targeting Aging Cells Improves Survival. Science (2021) 373(6552):281-2. doi: 10.1126/science.abi4474

241. Sargiacomo C, Sotgia F, Lisanti MP. COVID-19 and Chronological Aging: Senolytics and Other Anti-Aging Drugs for the Treatment or Prevention of Corona Virus Infection? Aging (2020) 12(8):6511-7. doi: 10.18632/ aging.103001

242. Seoane R, Vidal S, Bouzaher YH, El Motiam A, Rivas C. The Interaction of Viruses With the Cellular Senescence Response. Biology (2020) 9(12):455. doi: 10.3390/biology9120455

243. Kaur A, Macip S, Stover CM. An Appraisal on the Value of Using Nutraceutical Based Senolytics and Senostatics in Aging. Front Cell Dev Biol (2020) 8:218. doi: 10.3389/fcell.2020.00218

244. Carpenter VJ, Saleh T, Gewirtz DA. Senolytics for Cancer Therapy: Is All That Glitters Really Gold? Cancers (2021) 13(4):723. doi: 10.3390/ cancers 13040723
245. Coppe JP, Desprez PY, Krtolica A, Campisi J. The Senescence-Associated Secretory Phenotype: The Dark Side of Tumor Suppression. Annu Rev Pathol (2010) 5:99-118. doi: 10.1146/annurev-pathol-121808-102144

246. Casel MAB, Rollon RG, Choi YK. Experimental Animal Models of Coronavirus Infections: Strengths and Limitations. Immune Netw (2021) 21(2):e12. doi: 10.4110/in.2021.21.e12

247. Jia W, Wang J, Sun B, Zhou J, Shi Y, Zhou Z. The Mechanisms and Animal Models of SARS-CoV-2 Infection. Front Cell Dev Biol (2021) 9:578825. doi: $10.3389 /$ fcell.2021.578825

248. Winkler MS, Skirecki T, Brunkhorst FM, Cajander S, Cavaillon JM, Ferrer R, et al. Bridging Animal and Clinical Research During SARS-CoV-2 Pandemic: A New-Old Challenge. EBioMedicine (2021) 66:103291. doi: 10.1016/ j.ebiom.2021.103291

249. Ehaideb SN, Abdullah ML, Abuyassin B, Bouchama A. Evidence of a Wide Gap Between COVID-19 in Humans and Animal Models: A Systematic Review. Crit Care (2020) 24(1):594. doi: 10.1186/s13054-020-03304-8

250. Veenhuis RT, Zeiss CJ. Animal Models of COVID-19 II. Comp Immunol ILAR J (2021). doi: 10.1093/ilar/ilab010

Conflict of Interest: The authors declare that the research was conducted in the absence of any commercial or financial relationships that could be construed as a potential conflict of interest.

Publisher's Note: All claims expressed in this article are solely those of the authors and do not necessarily represent those of their affiliated organizations, or those of the publisher, the editors and the reviewers. Any product that may be evaluated in this article, or claim that may be made by its manufacturer, is not guaranteed or endorsed by the publisher.

Copyright (C) 2021 Kaklamanos, Belogiannis, Skendros, Gorgoulis, Vlachoyiannopoulos and Tzioufas. This is an open-access article distributed under the terms of the Creative Commons Attribution License (CC BY). The use, distribution or reproduction in other forums is permitted, provided the original author(s) and the copyright owner(s) are credited and that the original publication in this journal is cited, in accordance with accepted academic practice. No use, distribution or reproduction is permitted which does not comply with these terms. 


\section{GLOSSARY}

anti-RNP Anti-ribonucleoprotein

anti-CCP Anti-cyclic citrullinated peptide

APOBEC1 Apolipo-protein B mRNA-editing enzyme catalytic polypeptide 1

ARDS Acute respiratory distress syndrome

C-ANCA Cytoplasmic antineutrophil cytoplasmic antibody

CCL Chemokine (C-C motif) ligand

CCR Chemokine (C-C motif) receptor

CD Cluster of differentiation

CD3 $\delta \quad$ T-cell surface glycoprotein CD3 delta chain

CD3e T-cell surface glycoprotein CD3 epsilon chain

CD16 Fc fragment of IgG, low affinity receptor III (Fc $\gamma R$ RIII)

CD45RA Protein tyrosine phosphatase, receptor type, $\mathrm{C}$ (long isoform)

CD57 3-beta-glucuronosyltransferase 1 (B3GAT1)

CD94 Killer cell lectin-like receptor subfamily D, member 1 (KLRD1)

CD107a Lysosomal-associated membrane protein 1 (LAMP-1)

CD169 sialoadhesin

CD247 T-cell surface glycoprotein CD3 zeta chain (CD3ל)

CNS central nervous system

COPD chronic obstructive pulmonary disease

CRP C-reactive protein

CXCL Chemokine (C-X-C motif) ligand

CXCR Chemokine (C-X-C motif) receptor

DC-SIGN Dendritic Cell-Specific Intercellular adhesion molecule-3-Grabbing Non-integrin

DDP4 Dipeptyl peptidase-4 inhibitor

DNA Deoxy-ribonucleic acid

dsRNA Double-stranded ribonucleic acid

ER Endoplasmic Reticulum

FABP4 fatty-acid binding protein 4

FADD Fas-associated protein with death domain

Ficolins Oligomeric lectins with subunits consisting of both fibrinogen (Fi)-like globular domains and collagen (Col)-like long thin stretches with lectin (Lin) activity

FcyRIII Fc fragment of IgG, low affinity receptor III (CD16)

FoxP3 Forkhead box P3

FVII Coagulation factor VII

FX Coagulation factor $X$

G-CSF Granulocyte colony-stimulating factor

GM-CSF Granulocyte/monocyte colony-stimulating factor

GSDME Gasdermin E

HDAC2 Histone deacetylase 2

HLA human leukocyte antigen

ICAM1 intracellular adhesion molecule-1

IFIT Interferon Induced proteins with Tetratricopeptide repeats,

IFN Interferon

IFNAR Interferon- $\alpha / \beta$ receptor

IL Interleukin

iNOs Inducible nitric oxide synthase
Continued

IP-10 (or Interferon gamma-induced protein 10

CXCL10)

IRF Interferon regulatory factor

ISGs Interferon-stimulated genes

KIRs Killer-immunoglobulin like receptors

KLRG1 Killer cell lectin-like receptor subfamily G member 1

LAG3 Lymphocyte activation protein 3

LCK Lymphocyte-specific protein tyrosine kinase

MAC mMembrane attack complex

MAP2K2 Dual specificity mitogen-activated protein kinase kinase 2

MASP Mannan-binding lectin serine protease

MBP Mannose-binding protein

MCP Monocyte chemoattractant protein

MDA-5 Melanoma differentiation-associated gene 5

MHC Major histocompatibility complex

MIP-1 Macrophage inflammatory protein 1

MLKL Mixed lineage kinase domain like

MPO Myeloperoxidase

MX1 Myxovirus resistance 1

NETs Neutrophil extracellular traps

NK cells Natural killer cells

NKG2A- NK group 2 member A-D

NKG2D

NLRP3 NLR family pyrin domain containing 3

NLRs Nucleotide-binding Oligomerization Domain (NOD)-Like Receptors

NO Nitric oxide

nsp Non-structural protein

p-ANCA Perinuclear antineutrophil cytoplasmic antibody

PAl Plasminogen activator inhibitor

PAR Protease activated receptor

PD1 Programmed cell death protein 1

PD-L1 Programmed death ligand 1

PF4 Platelet-factor 4

PRRs Pattern Recognition Receptors, PRTN3: proteinase 3 (PR3)

RIPK Receptor-interacting serine/threonine-protein kinase

RLRs Retinoic acid-Inducible Gene-I-Like Receptors

SPP1 Secreted Phosphoprotein 1 (Osteopontin)

STAT Signal transducer and activator of transcription

Tbet T-box protein expressed in T cells

TBK1 TANK-binding kinase 1

TCR T-cell receptor

Th T-helper

TIM3 T cell immunoglobulin mucin-3

TLR Toll-like receptor

TNF $\alpha \quad$ Tumor necrosis factor $\alpha$

TRAC T cell receptor alpha constant

TRBC T cell receptor beta constant

TRIM Tripartite motif-containing

UNC93B1 Unc-93 Homolog B1

VCAM1 Vascular cell adhesion protein-1

Vwf Von Wilebrand factor

ZAP70 Zeta-chain-associated protein kinase 70

ZO-1 Zonula occludens-1 